\title{
A Method for Evaluating Water-Level Response to Hydrologic Stresses in Karstic Wetlands in Central Florida, Using a Simple Water-Balance Model
}

By Edward R. German

\section{U.S. GEOLOGICAL SURVEY}

Water-Resources Investigations Report 96-4216

Prepared in cooperation with the

St. Johns River Water Management District and Volusia County

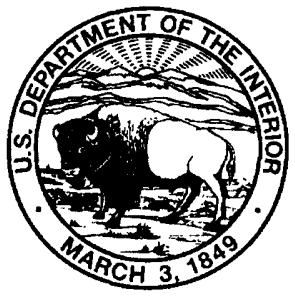




\title{
U.S. DEPARTMENT OF THE INTERIOR BRUCE BABBITT, Secretary
}

\author{
U.S. GEOLOGICAL SURVEY \\ Gordon P. Eaton, Director
}

The use of firm, trade, and brand names in this report is for identification purposes only and does not constitute endorsement by the U.S. Geological Survey.

For addtional information write to:

District Chief

U.S. Geological Survey

227 North Bronough Street, Suite 3015

Tallahassee, FL 32301
Copies of this report can be purchased from:

\section{U.S. Geological Survey}

Branch of Information Services

Box 25286, MS 517

Denver, CO 80225-0046 


\section{CONTENTS}

Abstract

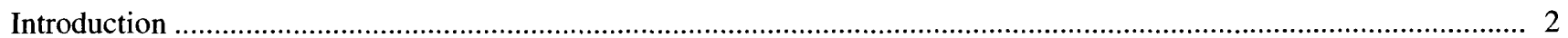

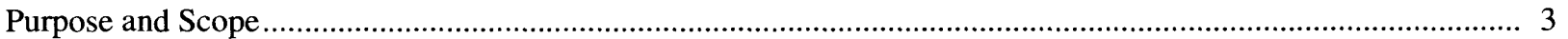

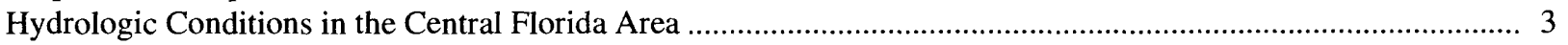

The Water-Budget Model for Simulating Streamflow and Water Levels in Wetlands ................................................ 8

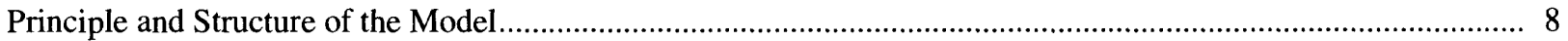

Specification of Surface- and Ground-Water Outflow Rates ........................................................................ 11

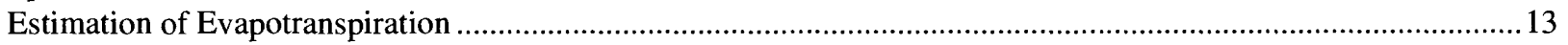

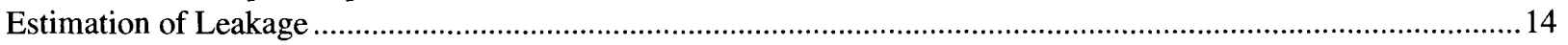

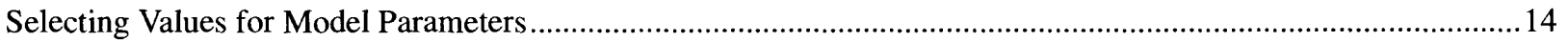

Application of the Model to a Wetland in Volusia County .................................................................................. 14

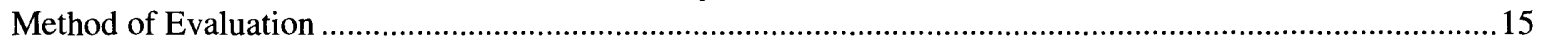

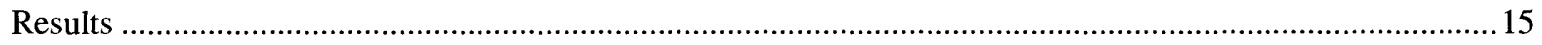

Application of the Model to Simulate Flows for Two Streams in Volusia County ................................................ 19

Application of Method for Characterizing Water Levels in Conceptual Wetlands .........................................................22

Sensitivity of Simulated Water Levels to Selected Model Parameters...................................................................26

Examples of Estimating Wetlands Response to Hydrologic Stresses ....................................................................26

Hypothetical Case 1: Effect of Withdrawal of Water from the Upper Floridan Aquifer

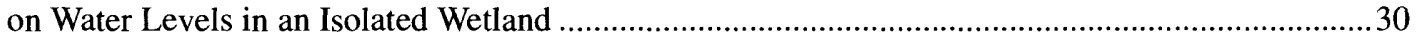

Hypothetical Case 2: Effect of Alteration of Wetlands Drainage-Basin Size .................................................32

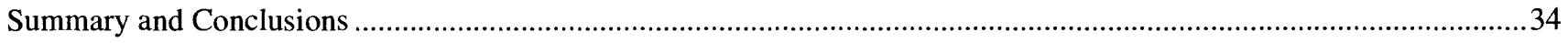

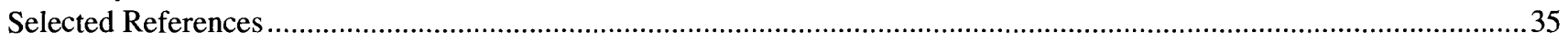

Appendix I - Representative Soil Characteristics for Some Central Florida Areas ..................................................39

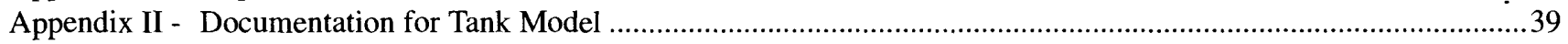

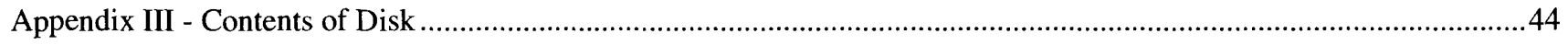

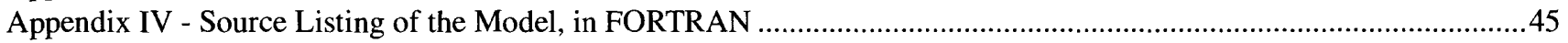

\section{FIGURES}

1. Map showing the central Florida area including watersheds and other locations mentioned

in this report .

2-5. Graphs showing:

2. Annual rainfall in central Florida, 1931-89................................................................................... 5

3. Monthly average potential evapotranspiration and rainfall for central Florida ......................................... 6

4. Distribution of daily rainfall at DeLand, 1931-89............................................................................. 7

5. Discharge duration curves for selected streams in Volusia and adjacent counties,

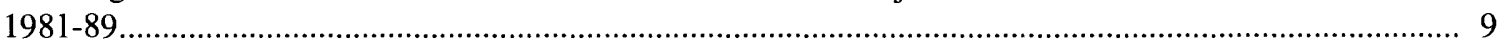

6. Diagram of the basic tank unit used by the water-budget wetlands model ..................................................... 10

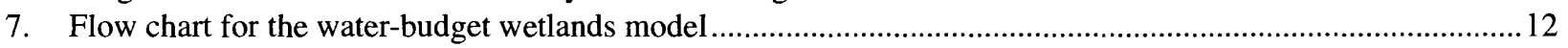

8-10. Graphs showing:

8. Hourly water level for 10-day periods beginning July 1, 1992, and June 1, 1993, at the HW44 well field.

9. Actual and simulated water table in the HW44 well field, June 20,1992, through June 30,1994 , using optimized values for field capacity, wilt potential, leakage, and extinction depth.

10. Cumulative-frequency distribution of actual and simulated water levels at the HW44 well field, June 20, 1992, to June 30, 1994 
11. Diagram of a three-tank model used to simulate streamflow

12. Graphs showing cumulative-frequency distribution of simulated and observed daily discharge at Blackwater Creek and Tiger Bay Canal.

13. Hydrograph showing simulated and observed daily discharge at Tiger Bay Canal, January 1981 through December 1989 .

14. Hydrograph showing simulated and observed daily discharge at Blackwater Creek, June 10, 1985, through December 31, 1989

15-19. Graphs showing:

15. The effect of extinction depth on simulated water levels, HW44 well-field model

16. The effect of field capacity and wilt potential on simulated water levels, HW44 well-field model

17. The effect of surface-inflow duration characteristics on simulated water levels, HW44 well-field model

18. Stage duration in a hypothetical wetlands with no surface inflow, for selected downward-leakage rates and surface-drainage rates

19. Stage duration in a hypothetical wetlands with selected wetlands area to drainage area ratios

\section{TABLES}

1. Parameters used in the water-budget model.

2. Summary of optimization runs for wilt potential, extinction depth, leakage, and field

capacity, HW44 well field, June 20, 1992, through June 30, 1994

3. Summary of optimization runs for daily discharge of Blackwater Creek and Tiger Bay Canal... 


\section{A Method for Evaluating Water-Level Response to Hydrologic Stresses in Karstic Wetlands in Central Florida, Using a Simple Water-Balance Model}

\author{
By E. R. German
}

\section{ABSTRACT}

There is a need for methods to rapidly assess the effects of developmental impacts on wetlands. A simple water-budget model was developed as a tool for the general understanding of factors affecting water levels in wetlands. The model was designed so that a hypothetical hydrologic system can be simulated as a series of tanks. Outflow from one tank can be directed into another tank linking the tanks together as desired. Simulated water levels in the tanks can be output to a file for plotting or other data analysis.

The model was evaluated by applying it to a wetland area in Volusia County, known as the HW44 well field, for June 1992 through June 1994. This is an isolated wetland that is not part of a well-defined stream system. Comparison of the cumulative-frequency distribution of actual and simulated water levels indicates that the simulated water table at the well field was almost always within 0.1 to 0.2 foot (ft) of the actual water table at any selected frequency of occurrence. The median simulated water table for the period was $39.08 \mathrm{ft}$ above sea level and the median actual water table was $39.13 \mathrm{ft}$ above sea level.

The model also was used to simulate daily surface discharge from two small streams in central Florida. The simulated daily discharges were distributed much like the actual discharges, especially for the stream which has a uniform streamflow distribution. Comparison of the simulated and actual daily discharges was not as good as that for cumulative-frequency distributions.
Part of the disagreement between simulated and observed daily discharge may be because the rainfall record is for a single station and may not be representative of the entire stream basins on a daily basis.

Two hypothetical cases were simulated to determine the effects of developmental impact on wetland water levels. These cases demonstrate the way in which the model might be used to gain a general understanding of possible developmental effects.

In the first simulation, the effect of lowering the potentiometric surface of the Floridan aquifer system on water levels in an isolated wetland is considered. In this case, the effect of increasing the head difference between the surficial aquifer system and the Upper Floridan aquifer by $10 \mathrm{ft}$ over the entire wetland was evaluated. The results indicate that the increased head difference of $10 \mathrm{ft}$ would lower minimum water levels by about $1 \mathrm{ft}$, median water levels would be lowered about $0.5 \mathrm{ft}$, and maximum water levels would be nearly unaffected by the pumping.

In the second simulation, the effect of reducing the drainage area of a stream feeding a wetland is considered. The hypothetical wetland receives water from direct precipitation and from streamflow with a drainage area/wetland area ratio of 10 . The effect of reducing the drainage area by a factor of 2 is considered. The reduction in drainage area on minimum water levels caused no noticeable effect. The minimum water levels were estimated to be about $4 \mathrm{ft}$ below land surface both before and after the hypothetical alteration. The simulations indicate that the median water levels would decrease by $0.2 \mathrm{ft}$ or less and the 
maximum water levels would decrease by more than $1 \mathrm{ft}$. The hydroperiod would be slightly shortened.

The model described in this report uses a very simple conceptualization of wetland hydrology. Models of much greater complexity, including extensive descriptive information about the watershed being modeled, would make more accurate simulations of water levels in actual wetlands but require extensive time to setup, calibrate, and run on a site-by-site basis. The intended purpose of the model described in this report is to give users a simple tool to understand wetlands hydrology in a semi-quantitative way and to determine the relative sensitivity of a system to developmental impacts.

\section{INTRODUCTION}

Wetlands are among the most prominent ecological features of the State of Florida and have been designated as areas worth preserving. These wetlands include several large and well-known systems such as the Everglades, Big Cypress Swamp, the St. Johns River marsh, coastal marshes, and the wooded flat lands throughout the State. Two major problems are associated with development that could affect these wetlands. One problem is that water supplies in many areas are pumped from the Upper Floridan aquifer and nearly all of the freshwater in the Upper Floridan aquifer is derived from possible recharge in wetland areas. Drawdown of the potentiometric surface of the Floridan aquifer system could lead to increased leakage from the surficial aquifer down into the Floridan aquifer system, thereby causing water levels in wetlands to decline. The other problem that may affect wetland water levels is the development of urban and agricultural areas, with the subsequent requirement for improving surface drainage. Improvements in surface drainage could affect wetland water levels by decreasing the quantity of water stored on the land surface.

The evaluation of potential effects of development on the hydrology of wetlands is difficult because the hydrologic processes of wetland systems and the interrelations between components of the processes are complex, nonlinear, and contain coupled elements. Attempts have been made to use areal ground-water flow models to predict changes in wetland water levels, but such models are extremely complex, difficult, and time-consuming to set up, calibrate, and run on a site-by-site basis. Consequently, they are not useful in making rapid assessments of developmental impacts.

A method that would allow rapid assessment of developmental impacts would not give a complete analysis of wetlands response to development; however, such a method would give managers and decision makers a screening tool to determine locations and situations where further study would be needed before considering planned developments. Ideally, the method should require minimal hydrologic information about an area of interest, yet have the capabilities to assess a wide range of development types. Such a method is described in this report. The method was developed by the U.S. Geological Survey (USGS) in a 3-year study that began in 1991 in cooperation with the St. Johns River Water Management District and Volusia County.

The wetlands model described here uses a relatively simple set of input data to generate daily water levels in a wetland. Data requirements include daily rainfall for the period of simulation, a file of mean monthly potential evaporation, and values for eight parameters that describe the soil or drainage characteristics of the wetlands.

Because of the simplicity of this model, it is not applicable to all wetlands. The two most limiting assumptions of this model probably are those used to compute surface runoff and to estimate evapotranspiration $(\mathrm{ET})$ from the unsaturated zone.

Conceptually, surface runoff does not occur until the water table reaches land surface. Therefore, this model is applicable only to wetlands that receive drainage from flat, sandy watersheds that have negligible direct surface runoff. The model is not applicable to wetlands that receive significant drainage from impervious areas - such as urban developments-or from areas of high topographic relief or relatively impervious soils where land slopes are great enough that significant amounts of overland flow occur even when the water table is below land surface.

Soil moisture is accounted for by assuming a single, unsaturated layer, rather than dividing the unsaturated zone into multiple discreet layers. The soil is assumed to be uniform in porosity and moistureholding ability, making the entire moisture content in the soil available to satisfy the requirement for soil ET, regardless of depth. Therefore, the model should not be used to represent areas where the unsaturated zone is more than a few feet thick. 


\section{Purpose and Scope}

The purpose of this report is to describe the development and use of a simple water-budget model for simulating wetland surface and ground-water flows and water levels. Use of the model is demonstrated by simulating water levels for a wetland in Volusia County (the HW 44 well field) and for simulating surface runoff from two watersheds (Blackwater Creek and Tiger Bay Canal) selected to represent the distribution of daily discharge typical of the central Florida area (fig. 1). A sensitivity analysis of the model is presented which indicates the effects of varying selected model parameters on simulated water levels in hypothetical wetlands. Listed in the appendix of this report is the FORTRAN code for the model, including descriptions of the file structures and data formats necessary for running the model. A 3.5-inch (in.) floppy disk is included with this report and contains the FORTRAN source code with a set of daily rainfall and potential evapotranspiration (PET) data.

The model was developed to fill a need in the central Florida area (specifically, Volusia County). However, the model may be useful in any other areas with hydrologic characteristics that are similar to those in Volusia County.

\section{Hydrologic Conditions in the Central Florida Area}

Model use requires a file of daily rainfall data. A 59-year record of daily rainfall was compiled and used for some of the simulations described in this report. The rainfall data are from stations operated by the National Oceanic and Atmospheric Administration (NOAA) at DeLand, Sanford, Orlando, and Eustis. These data were combined to form a single set of data because none of the stations had complete daily record for the entire 58-year period. The daily data are mostly for the DeLand station. During periods of missing data for DeLand, data for the other stations were substituted. The preferential order of substitution was Sanford, then Orlando, then Eustis.

Annual rainfall for the period 1931-89 ranged from 40.8 to 75.5 in. and averaged 55.4 in. (fig. 2). The annual rainfall average is somewhat high in comparison with other peninsular Florida sites (L. Knowles, USGS, oral commun., 1995). For example, average rainfall for Orlando for the period 1948-89 was only $51.2 \mathrm{in}$. The readily available moisture in extensive wetland areas close to Deland could be a source of moisture to the atmosphere that could increase rainfall in the study area.

Rainfall was averaged, on a monthly basis, over the 58 years. Results indicate that the rainfall distribution has a seasonal pattern typical of peninsular Florida. More than half of the total annual rainfall is in June through September. Each of these months had an average rainfall of nearly 7 in. or more (fig. 3). Maximum daily rainfall for the period was $8.75 \mathrm{in}$. By determining cumulative distribution, the contribution from large storms relative to the total accumulation of rainfall is defined. Days with a total rainfall of less than 1 in. accounted for about 85 percent of the days with rain, but only about half the total volume of rainfall (fig. 4). In contrast, storms with rainfall greater than 1 in. contributed half the cumulative rainfall, although they make up only 15 percent of all storms.

The model requires estimation of daily ET. Long-term pan-evaporation data are not as readily available as are rainfall data. Lisbon and Gainesville are the only two stations in or near the central Florida area with several years of pan-evaporation data. Panevaporation measurements began in 1960 at Lisbon; in Gainesville, measurements began in 1953 and were discontinued in 1988.

The pan-evaporation data were used to estimate PET by using monthly pan coefficients determined in studies on Lake Okeechobee (Kohler, 1954). The coefficients were based on comparison of pan- and lake-evaporation data and range from 0.71 in November to 0.91 in July and August. These pan coefficients were used to convert pan evaporation (average for Lisbon and Gainesville stations) to PET. The estimated evaporation rate ranged from 2.08 inches per month (in/mo) (0.067 inches per day (in/d)) during January to $6.26 \mathrm{in} / \mathrm{mo}(0.20 \mathrm{in} / \mathrm{d})$ during July (fig. 3$)$. The seasonal pattern of evaporation is well-defined, with 6 or more in/mo of evaporation from April through August, and slightly more than 2 in/mo from November through February.

Characterization of streamflow is important to model simulations involving a wetland fed by a stream. A streamflow generator that simulates streamflow typical of streams in central Florida is described later in this report. Streamflow characteristics include duration, or distribution of streamflow in time, as well as magnitude of flow. Some streams have a relatively uniform daily discharge, whereas others are more "flashy" and react rapidly to rainfall, then return to 


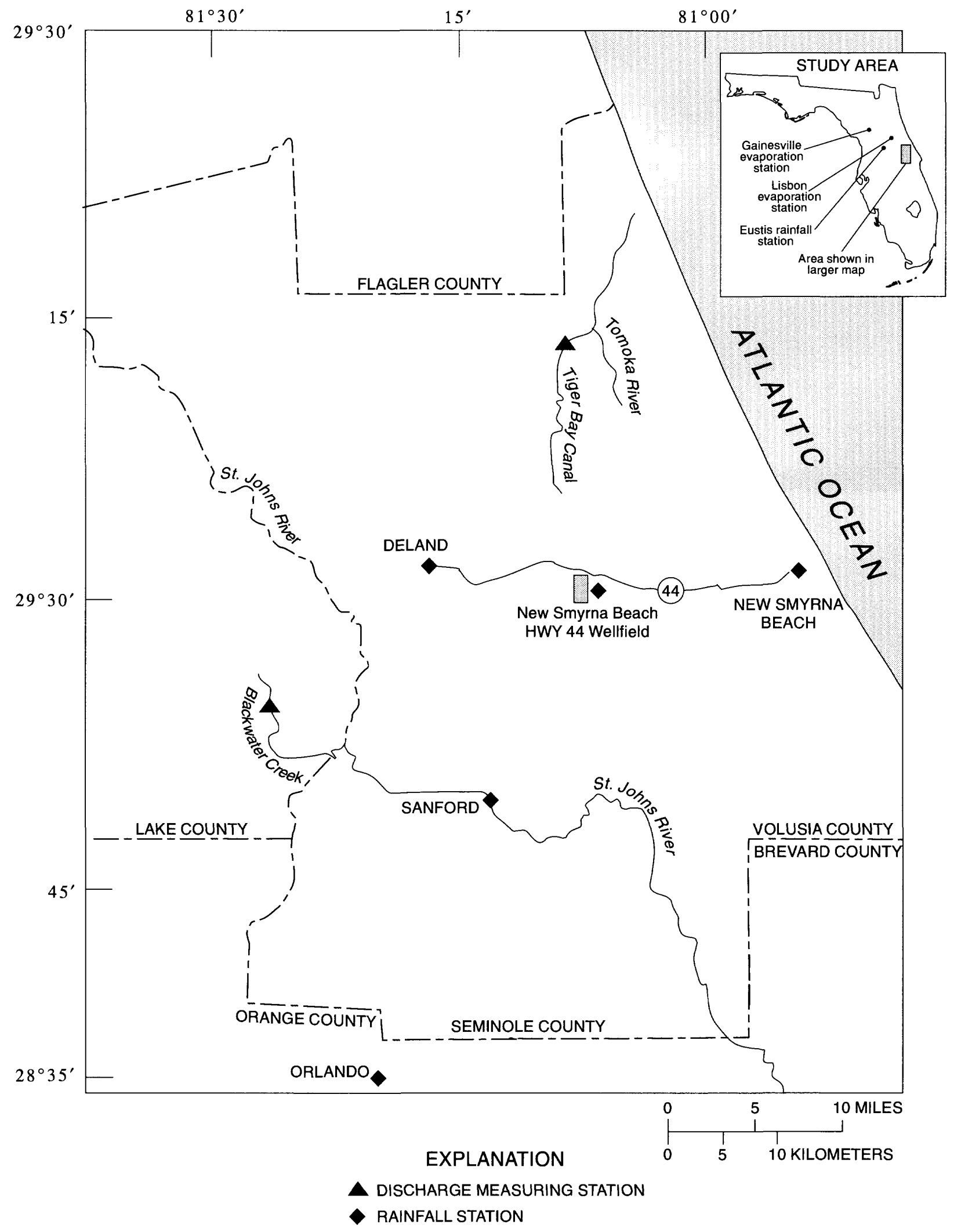

Figure 1. Central Florida area including wetlands and locations mentioned in this report. 


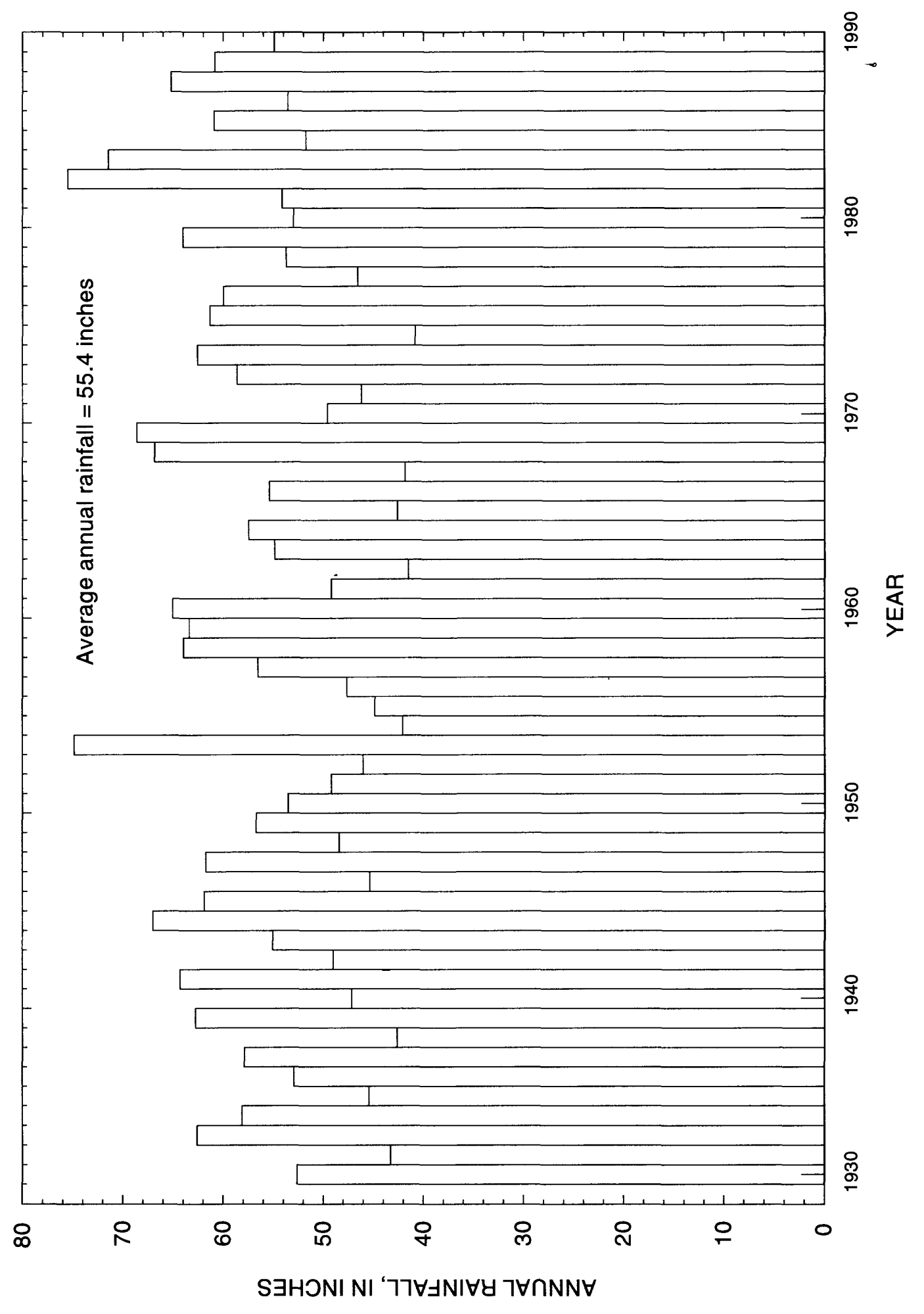

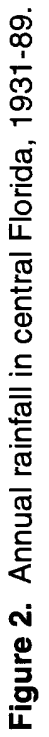



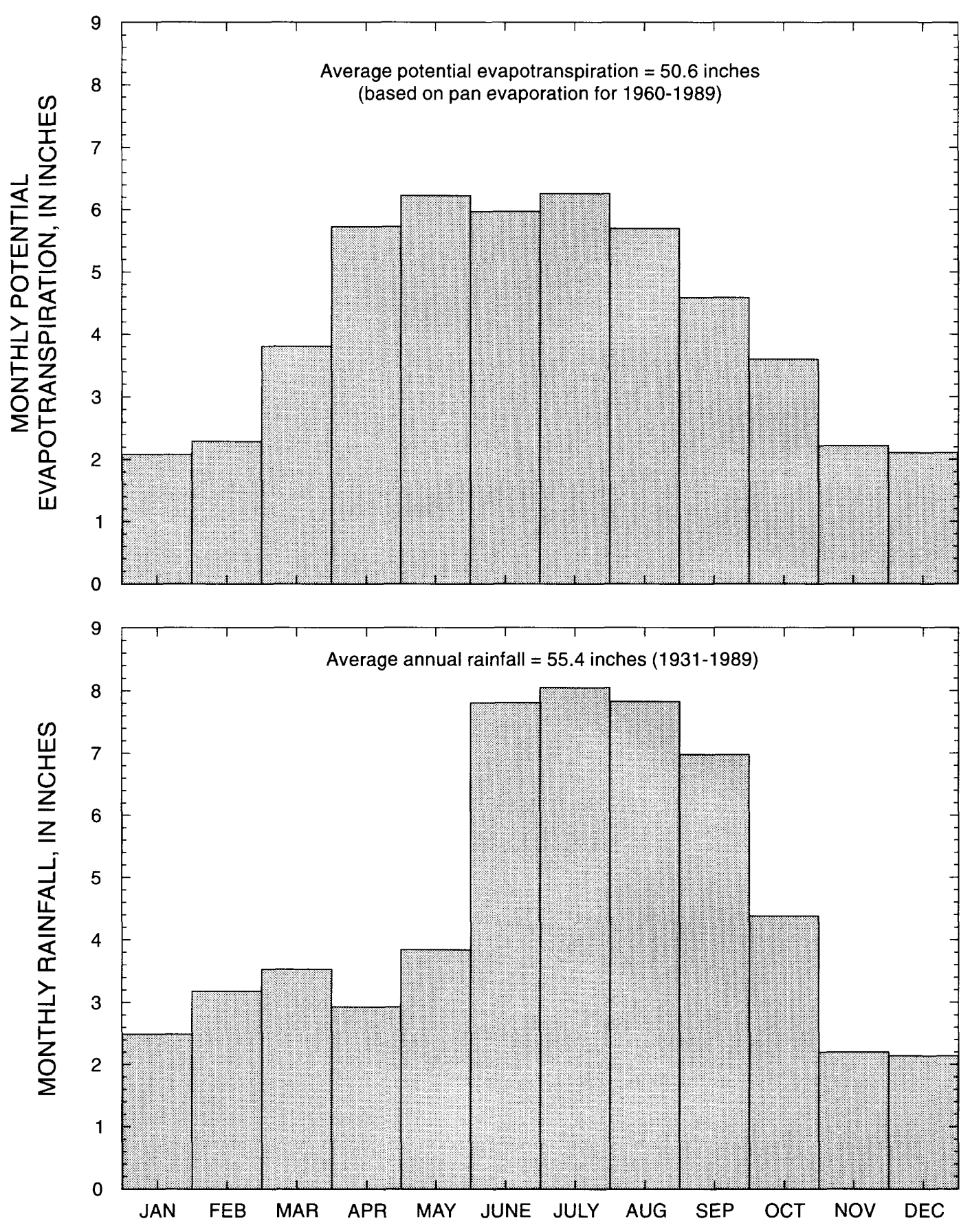

(Rainfall was compiled from daily records for DeLand, Sanford, Orlando, and Eustis. Potential evapotranspiration is estimated from average pan evaporation for Lisbon and Gainesville, using a monthly coefficient (Kohler, 1954).)

Figure 3. Monthly potential evapotranspiration and rainfall for central Florida. 


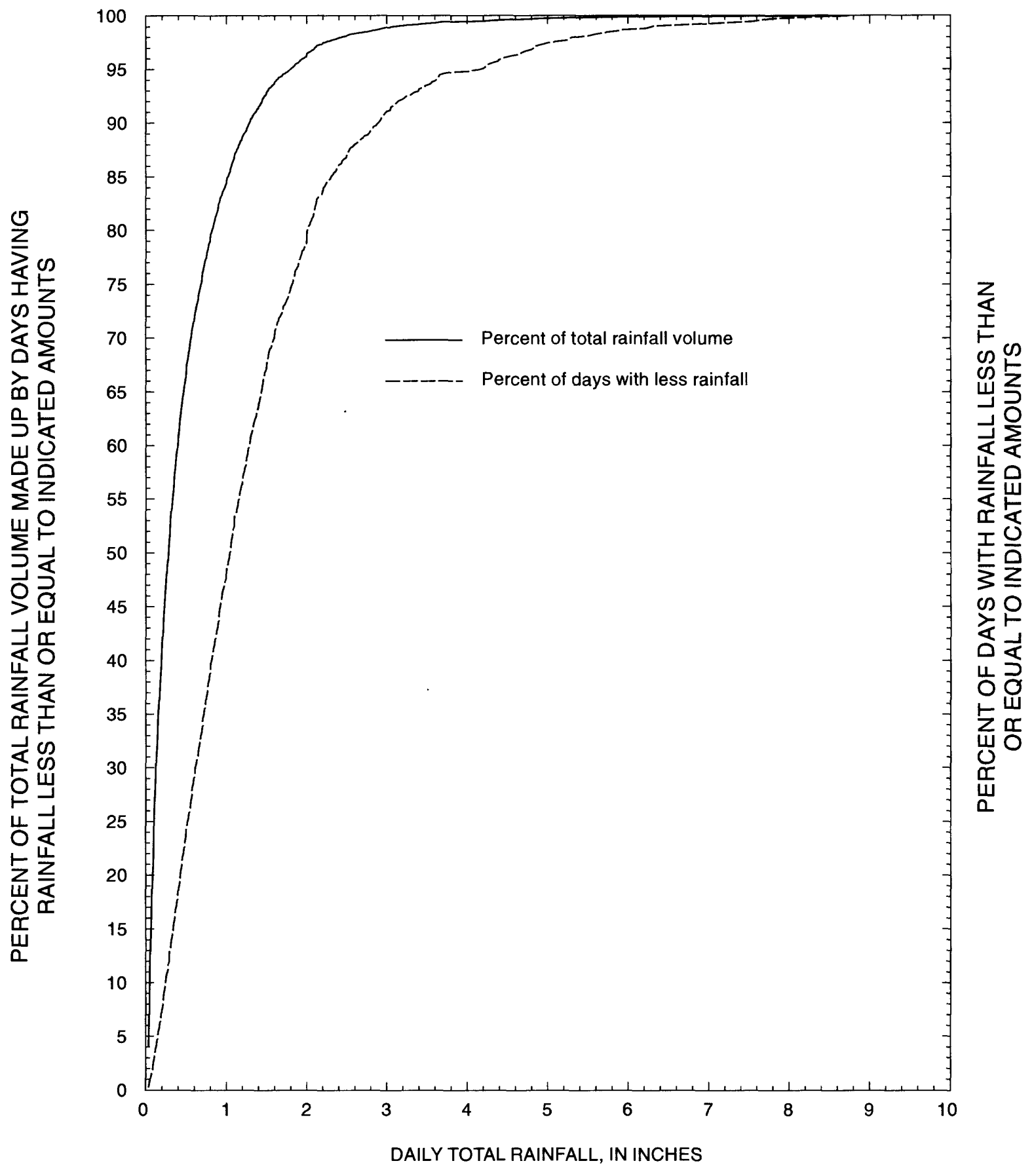

Figure 4. Distribution of daily rainfall at DeLand, 1931-89. 
low or no flow soon after the end of rainy periods. Streams that drain basins with small slopes and relatively large amounts of surface storage in lakes and wetlands-typical of peninsular Florida-generally have more uniform streamflow than streams that drain steeper areas and areas with little surface storage. The frequency distribution of daily streamflow can vary even within the wetland areas of central Florida, as shown by the cumulative-discharge hydrographs for eight streams (fig. 5). Each of these streams has at least a 5-year record of daily discharge during 1981-89. These streams probably are representative of the range of flow distributions of streams draining central Florida.

Discharge data for Blackwater Creek and Tiger Bay Canal represent the two extremes among the eight streams (fig. 5). Discharge in Blackwater Creek is relatively well-sustained, with lower discharges accounting for a relatively large part of the total discharge volume. In Blackwater Creek, discharges that were not exceeded 50 percent of the time contributed about 18 percent of the total volume during the 1981-89 period. In contrast, discharges in Tiger Bay Canal were poorly sustained, and discharges that were not exceeded 50 percent of the time accounted for only about 1 percent of the total volume of discharge. Thus, the relatively low discharges contributed more of the discharge volume in Blackwater Creek than in Tiger Bay Canal.

\section{THE WATER-BUDGET MODEL FOR SIMULATING STREAMFLOW AND WATER LEVELS IN WETLANDS}

The water-budget model described in this report is a simulation model of a conceptual hydrologic system in which water inflows and outflows are accounted for using simple mathematical relations. Simple models of this type commonly are used in various ecosystem simulations where an analytical model using more exact (but much more complex) mathematical representation of processes would be impractical (Hall and Day, 1977).

The model requires a file of daily rainfall data for the period being modeled, a file of average PET for each month of the year, and specification of parameters describing the watershed. The user-defined parameters in this model are listed in table 1.

Output from the model is simulated daily water level or discharge, as well as a summary of total water quantities for the components of the water budget. The model also outputs the hydroperiod, which is the number of days that the water level was above the land surface.

\section{Principle and Structure of the Model}

The basic principle of this water-budget model is that all rainfall and inflow to a model unit (tank) infiltrates into the soil unless the water level in the tank is above the defined land surface. Incoming water goes into storage in the soil until the soil capacity is exceeded, then the water is added to the water table. Surface runoff is simulated when the water level is above land surface. ET is taken from both the water table and the soil when the water level is below land surface, and from the water surface when the water level is above land surface. This water-budget model differs from more complex watershed models because it does not account for any direct runoff from the land surface, unless the water table is at or above the land surface. This assumption of zero direct runoff probably is applicable to many central Florida watersheds because of the highly conductive soils and relatively flat watershed slopes that are characteristic of the area. However, it may not be applicable to urbanized areas or areas with relatively steep land slopes and impervious soils.

The basic unit of the model is shown in figure 6 . The model simulates daily water levels and fluxes in the unit in response to daily input of rainfall, surface inflow, and ground-water inflow; and daily output of ET, surface outflow, ground-water outflow, and leakage to the underlying Floridan aquifer system.

Although figure 6 depicts a single unit, in most cases a conceptual watershed would be simulated by using two or more units linked together so that the output from one unit is directed to the input of some other unit. The model is structured so that any number of tank units and sizes may be defined, and interconnections between tanks may be defined so that any unit may receive inflow from any other unit. By using multiple tanks, a watershed may be considered as a system of interconnected subbasins with different properties.

The model uses a numeric computational method, rather than an analytical solution that is specific to each desired configuration. A basic water budget is computed for each defined tank unit, with the outflow from one tank being routed into other tanks as specified by the user. One problem inherent with this type of solution is that the model carries out the budget 


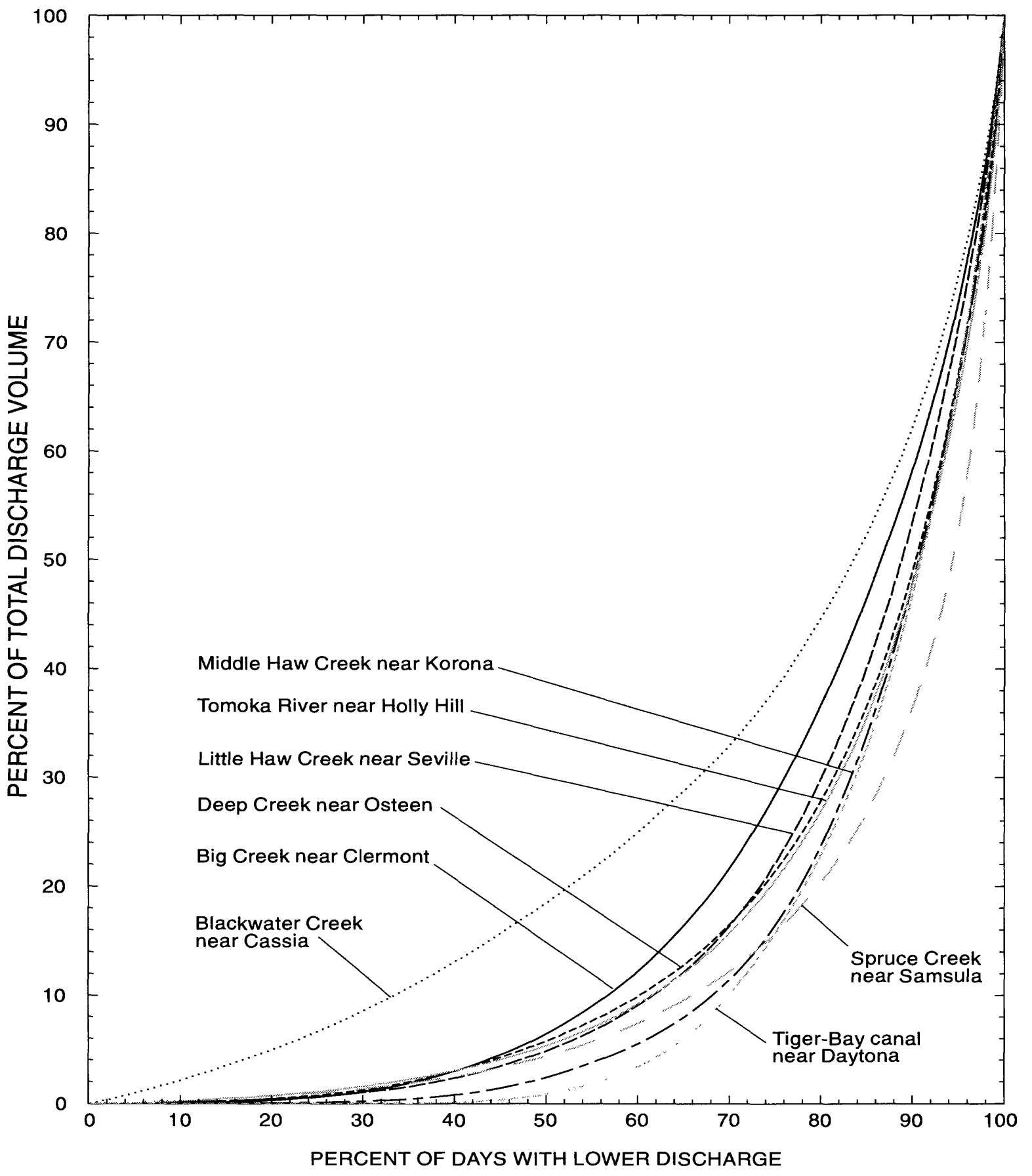

Figure 5. Discharge duration curves for selected streams in Volusia and adjacent counties, 1981-89. 


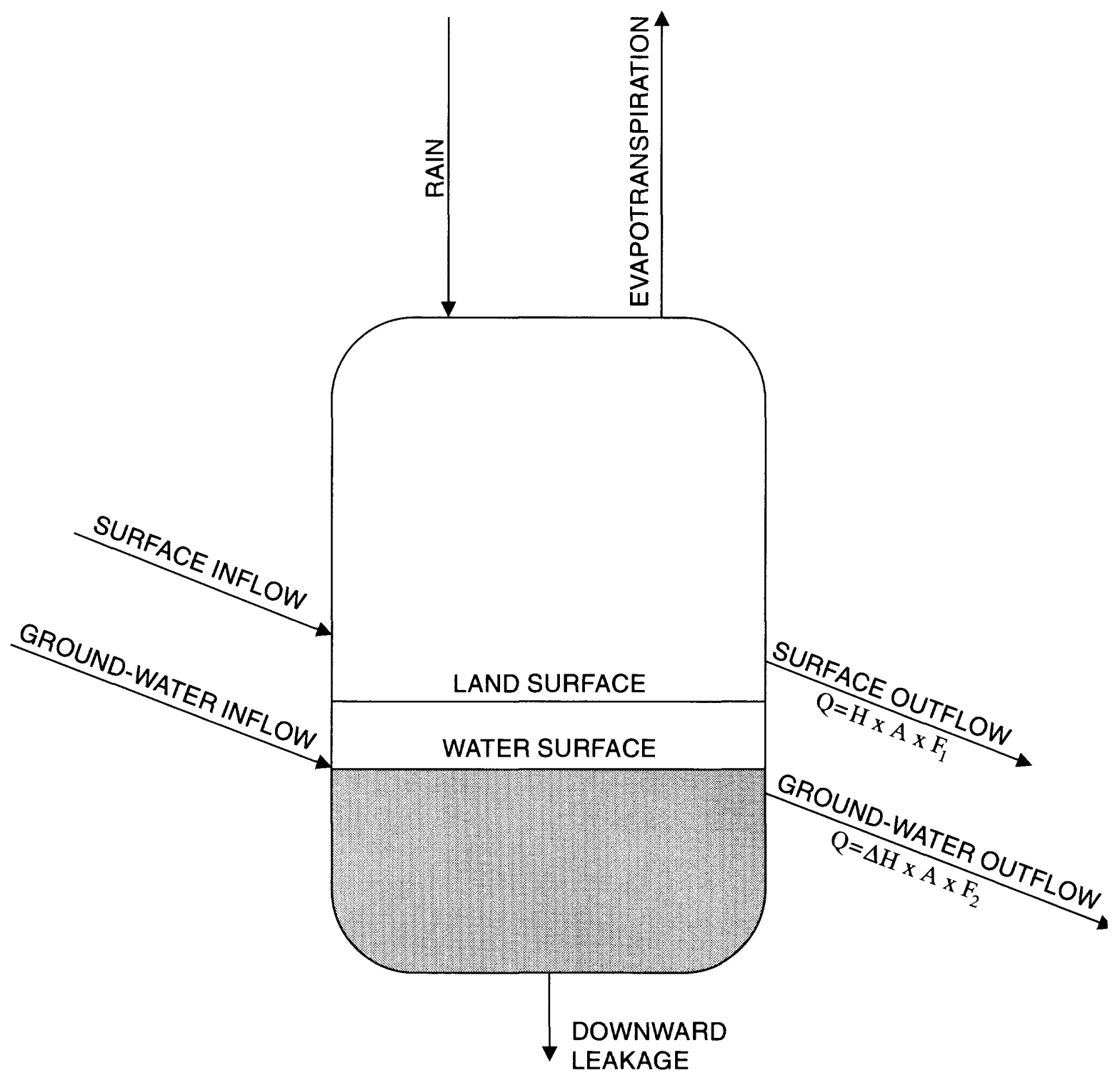

( $Q$ is the outflow rate, $\mathrm{H}$ is the depth of water above land surface, $A$ is the cross-sectional area, $F_{1}$ is the surface outflow rate constant, $\Delta \mathrm{H}$ is the difference in water levels between the outflow tank and the tank receiving the outflow, and $\mathrm{F}_{2}$ is the ground-water outflow rate.)

Figure 6. Diagram of the basic tank unit used by the water-budget wetlands model. 
Table 1. Parameters used in the water-budget model

\begin{tabular}{|c|c|}
\hline Parameter: & Meaning \\
\hline Pore & $\begin{array}{l}\text { The effective porosity of the surficial aquifer and overlying soil. (Dimensionless ratio of } \\
\text { interconnected void space to total soil volume) }\end{array}$ \\
\hline Fcap & $\begin{array}{l}\text { The field capacity of the soil, or the maximum amount of moisture the soil can hold before down- } \\
\text { ward percolation takes place. (Dimensionless fraction of total porosity: } 0 \text { if the soil can hold no } \\
\text { moisture, or any intermediate value up to } 1 \text { if the maximum water content is equal to the effec- } \\
\text { tive porosity) }\end{array}$ \\
\hline Wilt & $\begin{array}{l}\text { The wilting capacity of the soil, or the minimum moisture content, below which ET cannot be } \\
\text { extracted. (Dimensionless fraction of effective porosity: } 0 \text { if all moisture can be removed from } \\
\text { the soil or any intermediate value up to } 1 \text { if the minimum moisture content is equal to the effec- } \\
\text { tive porosity) }\end{array}$ \\
\hline Exd & The extinction depth, or the depth below which no ET is assumed to take place. (Feet) \\
\hline Rleak & $\begin{array}{l}\text { The downward-leakage rate from the surficial aquifer system to the Upper Floridan aquifer. (Feet } \\
\text { per day) }\end{array}$ \\
\hline Area & $\begin{array}{l}\text { The surface area of the tank, in square miles, or dimensionless if output of discharge in inches is } \\
\text { selected. If output of discharge in inches is selected, then relative tank sizes may be specified. } \\
\text { Generally, the downstream tank is given a size of } 1 \text {, and the upstream tanks are given sizes that } \\
\text { reflect the drainage area relative to the downstream tank }\end{array}$ \\
\hline $\mathrm{F}_{1}$ & The watershed coefficient relating surface outflow rate to storage. (1/days) \\
\hline $\mathrm{F}_{2}$ & The watershed coefficient relating ground water outflow rate to storage. (1/days) \\
\hline
\end{tabular}

calculations in a specific and unvarying order and, therefore, the computed results are dependent upon the order in which the terms in the water budget are considered. For example, if rain is added to a tank before evaporation is taken out, water levels are higher and thus more subject to evaporation than if evaporation is taken out before adding rain. The model was made less dependent on this order of operation by subdividing each day into a user-selected number of intervals, with water-budget accounting for each interval. The use of interconnected tank units in a conceptual model makes the order of computation even more of a factor in output. Study of water-budget error for a selected number of computational intervals indicated that 30 or fewer intervals per day were adequate to minimize waterbalance errors for a single-tank conceptualization. For a conceptualization using interconnected tanks, a much greater number of iterations may be required to achieve acceptable water-balance errors. A flow chart of the model is shown in figure 7.

\section{Specification of Surface- and Ground-Water Outflow Rates}

Surface discharges from one tank to another are simulated using the linear reservoir principle in which the quantity of surface water in a tank is directly proportional to the outflow (Chow, 1964). The relation is:

$$
S=K \times Q
$$

where

$S$ is the quantity of water (water level above land surface),

$K$ is the reservoir constant, and

$Q$ is the surface outflow rate.

The linear-reservoir principle carries the assumption that the value of $K$ is independent of storage.

Previously, the linear-reservoir principle was used in surface-water models by assuming that a drainage basin consists of interconnected linear reservoirs. Nash (Chow, 1964) derived an analytical solution for modeling outflow from a set of identical linear reservoirs connected in series. Kulandaiswamy (Chow, 1964) derived solutions for outflow from various networks of linear reservoirs connected in series and parallel arrangements. These and other applications of the linear-reservoir principle are discussed in hydrology texts such as Chow (1964). 


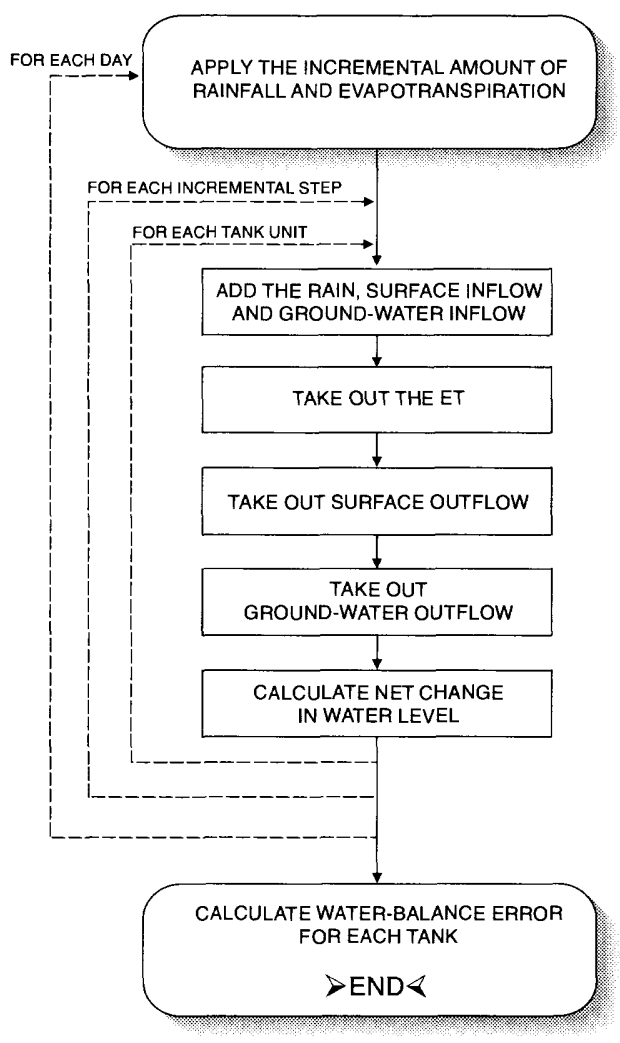

Figure 7. Flow chart for the water-budget wetlands model.

In this model, the linear-reservoir relation is rearranged from Chow (1964), and used in the following form:

$$
Q_{i}=H_{i} \times A \times \frac{F_{1}}{N}
$$

where

$Q_{i}$ is the discharge for the interval of computation (in units of length cubed per time),

$H_{\mathrm{i}}$ is the depth of water (length) at the beginning of the computation interval,

$A$ is the cross-sectional area of the tank (length squared),

$F_{1}$ is the discharge rate constant (1/time), and

$N$ is the number of intervals into which the time unit is divided.

Equation 2 can be written in a differential form for a daily computational interval as:

$$
d V / V=-F_{1} d T
$$

where

$V$ is the volume (length cubed) of water in the tank, and

$T$ is time.

Integration of equation 3 gives the following equation relating $V$ to $V_{o}$ :

$$
V=V_{o} \times e^{-F_{1} \times T},
$$

where

$V_{o}$ is the volume in the tank at $T=0$.

Rearranging equation 4 and setting $V=V_{o}$ gives the following equation relating the value of $F_{1}$ to the days required for the volume of water in the tank to decrease to half of the volume at $T=0$ :

$$
T_{l / 2}=\frac{\ln (0.5)}{F_{1}}=\frac{0.693}{F_{1}},
$$


$T_{1 / 2}$ is also the time required for the discharge to decrease to half of the discharge at $T=0$ because discharge is proportional to volume. The discharge (and volume) half life is given in the following table for selected values of $F_{l}$ :

\begin{tabular}{cc}
\hline $\begin{array}{c}\text { Value for } \boldsymbol{F}_{\boldsymbol{1}}, \\
\text { in 1/days }\end{array}$ & $\begin{array}{c}\text { Discharge (volume) } \\
\text { half life, in days }\end{array}$ \\
\hline 0.01 & 69.3 \\
.05 & 13.9 \\
.1 & 6.9 \\
.2 & 3.5 \\
.3 & 2.3 \\
.5 & 1.4 \\
\hline
\end{tabular}

In routing outflow from one tank to another, the effects of backwater are not considered by this model. However, outflow is not added to a tank if the water level of the receiving tank is at or greater than the water level of the donating tank. This conceptualization is analogous to watersheds that are separated by a cascade section, so that water from the upstream part of the basin flows freely into the downstream part of the basin until the water levels are the same.

Ground-water flow from one tank to another is similar to that of surface-water flow. The groundwater outflow is computed by the relation:

$$
Q_{i}=\Delta H_{i} \times A \times \frac{F_{2}}{N},
$$

where

$\Delta H_{i}$ is the difference between water levels in the two tanks (length), and

$F_{2}$ is the rate constant (1/time) for ground-water outflow.

This method of calculating ground-water flow looks similar to Darcy's law of ground-water flow, but in actuality it is not similar. Darcy's law expresses ground-water flow rate as a function of gradient along the direction of flow, cross-sectional area of the aquifer, and the transmissivity of the aquifer. The main difference between equation 6 and Darcy's law is that in equation 6 , the area (A) is the surface area of the tank unit; and in Darcy's law, the area used is the crosssectional area of the aquifer through which the water is flowing. Equation 6, rather than Darcy's law, was chosen to represent ground-water flow to keep data requirements for model use at a minimum. Use of equation 6 requires only the ground-water flow-rate constant $F_{2}$, in addition to the other variables that are computed by the model or are needed for other parts of the model. Use of Darcy's law requires knowledge of aquifer transmissivity, thickness, cross-sectional area, and gradient along the flow path.

\section{Estimation of Evapotranspiration}

The monthly PET data are read from a file and used by the model for each day in the month. Estimation of the actual ET from the water table and the soil zone is difficult because of the complexity of wetland systems in terms of type and extent of plant cover, soil types, and transfer of solar radiation to the soil. The wetlands in central Florida generally have cypress stands and other areas of trees as well as open areas. Because these trees probably have roots that reach the water table, it is probable that ET is extracted from the water table and the soil zone at the same time. The functions used by this model assume that ET is extracted from both the water table and the soil zone according to the following simple relations. These relations are probably over-simplified because the actual processes are too complex to simulate with this model.

First, the $E T$ from the water table $\left(\mathrm{ET}_{\mathrm{wt}}\right)$ is computed using the relation:

$$
E T_{w t}=\operatorname{PET} \times\left(1-\frac{\text { Depth }}{\text { Exd }}\right)
$$

where

$P E T$ is the potential evapotranspiration (in.) at the land surface,

Depth is the depth (ft) from land surface to the water table, and

Exd is the extinction depth ( $\mathrm{ft}$ ), or the maximum depth at which $E T$ can be extracted from the water table.

If the water-table depth is greater than the extinction depth, then $E T_{w t}$ is zero.

The PET that is not taken from the water table is taken from the soil $\left(E T_{\text {soil }}\right)$ according to the relation:

$$
E T_{\text {soil }}=\left(P E T-E T_{w t}\right) \times 2 \times\left[1-\frac{1}{S M+1}\right],
$$

where

$S M$ is the volume fraction of water contained in the soil.

Thus, if the soil is saturated $(S M=1)$, all of the $P E T$ not taken from the water table $\left(E T_{w}\right)$ is taken from the soil (if the soil moisture is adequate to satisfy 
the $\left.E T_{\text {soil }}\right)$, and the soil moisture is decreased by that amount. If $S M=0$, then no $E T$ is taken from the soil and the remaining $P E T$ not taken from the water table is unused. If the soil does not contain enough moisture to satisfy the $E T_{\text {soil }}$, then the soil moisture is set to the specified wilt capacity and the remaining $E T_{\text {soil }}$ is unused.

\section{Estimation of Leakage}

Leakage is the rate of downward movement of water from the surficial aquifer system to the Floridan aquifer system and is proportional to the head difference between the two aquifers. This head difference could vary seasonally in some locations, resulting in a variable leakage. In wetland areas, leakage rates probably are very low in comparison to other components of the water budget. For this reason, a user-selected value for leakage is used in the model. This assumption of constant leakage should be acceptable for most model uses and can be evaluated by comparing total leakage values with total outflow values for a model run. If leakage is an important part of the water budget and if the head difference between the surficial aquifer system and the Floridan aquifer system varies seasonally by a large amount, then the model would need to be modified to estimate daily leakage from a record of the actual head differences.

\section{Selecting Values for Model Parameters}

In addition to input-data files of daily rainfall and monthly means of daily ET, values of the parameters given in table 1 are required. In using this model as a preliminary assessment tool, there will probably be little specific information available regarding soil properties and surface- and ground-water drainage rates. In such cases, it will be necessary to use representative values for some parameters, such as soil properties, and "calibrate" the model to obtain values for other parameters that result in fitting what is known about the area.

Some values for soil porosity (Pore), and maximum and minimum soil moisture contents (Fcap and Wilt), are given in Appendix I for soils characteristic of central Florida. Leakage rates may be calculated by multiplying leakance values by the head difference between the surficial aquifer system and the Upper Floridan aquifer. Leakance values based on calibration of ground-water flow models for central Florida have been reported by Tibbals (1990) and Murray and Halford (1996).

Values of $F_{1}$ and $F_{2}$ are a function of basic hydraulic characteristics and size and in most cases will be determined by model calibration. In the case where a simple single-tank conceptualization could represent a wetland, the $F_{l}$ rate constant might be evaluated by observing water level and determining the time required for the mean water depth in the wetland to drop to half of a selected value. Equation 3 could then be solved for the value of $F_{1}$. If the effects of downward leakage and ET could be accounted for, observation of ground-water levels to similarly determine the value of $F_{2}$ would also be possible. In most cases, however, it probably would be necessary to arrive at values of $F_{1}$ and $F_{2}$ through model calibration, in which a range of values for these parameters would be tried to determine which values result in the most reasonable predictions of water level. In some cases, it is possible to make an approximation of the mean ground-water flow rate by considering mean gradients. Then the value of $F_{2}$ could be adjusted until the ground-water flow rates simulated by the model would be compatible with the estimates of mean flow rate.

\section{Application of the Model to a Wetland in Volusia County}

The water-budget model was evaluated by using it to simulate water levels in the surficial aquifer system in an isolated wetland area (referred to as the HW44 well field) in Volusia County (fig. 1). The HW44 well field is on the eastern side of Talbot Terrace, a poorly drained, flat marine terrace lying between Rima Ridge to the east and DeLand Ridge to the west. The elevation of Talbot Terrace generally is about 42 feet (ft) above sea level (Cooke, 1945); in the vicinity of the HW44 well field, it is only about $5 \mathrm{ft}$ lower than Rima Ridge. The well field is in a pine flatland with widely scattered pine trees and predominated by grasses and palmetto. The area contains scattered cypress domes at slightly lower locations. Rainfall data, surficial aquifer system water levels, and Upper Floridan aquifer water levels have been recorded at the well field since June 1992.

The well field is not subject to widespread frequent inundation, although each year the water table probably reaches land-surface depressions. During this study, water was never observed to cover the entire 
area, although this could probably occur during some years. Because there are no well-defined stream channels in the well-field area, water moves into and out of the area by sheet flow and through interconnected low areas. The direction of surface-water flow is not known because of low.slopes and manmade modifications within the area.

\section{Method of Evaluation}

The well-field area was modeled as a singletank unit (fig. 6) with no surface or ground-water inflow. An optimizer algorithm (Press and others, 1989) was used to find the values of four model parameters-Fcap, Wilt, Exd, Rleak (table 1)-that resulted in the best agreement between observed and simulated water levels. The optimizer works iteratively, starting with user-supplied estimates of parameter values and estimating new parameter values until the sum of the squares of differences between observed and simulated day-end water levels are constant within a specified tolerance.

Some model parameters were set to constant values. Porosity was set to 0.40 , which is representative of sandy soils. The surface-outflow rate constant $F_{I}$ was set at $0.15 /$ d, a value that is probably representative of sluggish wetland drainage systems. Because no sheet flow of surface water was observed at the site, surface inflow to the wetlands was not considered. Also, no ground-water inflow was assumed.

Using the optimizer does not guarantee the "best" or most reasonable values for the parameters being optimized, and the best solution found by the optimizer may be highly dependent on the initial estimates of parameter values. For this reason, multiple optimization runs were made using as starting conditions all 16 possible combinations of maximum and minimum initial parameter estimates for the four parameters.

\section{Results}

The best fits for the 16 sets of initial estimates are summarized in table 2 . The root mean square errors indicate the closeness of the fit in describing the daily water levels, and is the square root of the daily mean square difference between simulated and actual day end water-table elevation. The root mean square errors ranged from 0.41 to $1.05 \mathrm{ft}$. Only 2 of the 16 runs had relatively low error sums (0.41 and 0.42$)$. These two sets of parameter values are very similar, with extinction depths of about $3.7 \mathrm{ft}$, field capacities of about 70 percent of total porosity, wilt potentials only slightly less than field capacity, and leakage of 0.0008 foot per day ( $\mathrm{ft} / \mathrm{d})$.

The relation of diurnal water-table fluctuation to depth tends to indicate an extinction depth of somewhat greater than $3.5 \mathrm{ft}$. The plots of hourly watertable elevation for nearly rainless periods during July 1-10, 1992 and June 1-10, 1993, show the effect of ET on the daily pattern of water-level fluctuation (fig. 8). The effect is especially evident in the data for July 1992 because the water table was within $1.5 \mathrm{ft}$ or less of the land surface. The pattern of fluctuation is characterized by a decline in water level beginning before mid-day and continuing for several hours. Later in the day, the decline in water level stops, and in some cases, recovers to a small extent during the early morning hours. This recovery probably was due to infiltration of surface water standing in cypress domes that was not noticeable during the days when ET was causing the water table to decline. The pattern of diurnal fluctuation was less evident during June 1-10, 1993, when the water table was about 2.7 to $3.5 \mathrm{ft}$ below land surface. The diurnal variation was nearly absent at a water-table depth of about $3.5 \mathrm{ft}$ below land surface. This almost complete lack of diurnal fluctuation at depths of about $3.5 \mathrm{ft}$ indicates that no ET was being extracted from the water table at that depth. This depth is in general agreement with the modeloptimized extinction depths.

The nearly equal values for wilt potential and field capacity indicated by the optimized model runs may indicate a system where water is permanently stored in the soil and any water removed by ET would be replaced by water drawn by capillary action from the water table. The constant presence of water in the soil acts to reduce the effective porosity, so that rainfall would be routed to the water table faster than total porosity would indicate.

The relatively high levels of moisture in soils of the HW44 wetland during a relatively dry period indicate that soil moisture may be maintained by water from the water table. Soil samples taken on May 21, 1993, had volumetric moisture contents of 31 percent at the surface, 18 percent at $1 \mathrm{ft}, 23$ percent at $2 \mathrm{ft}$, and 35 percent at $3 \mathrm{ft}$ (just above the water table). Averaged over the unsaturated thickness of the soil (about $3 \mathrm{ft}$ ), the total amount of moisture contained in the soil on the sampling date would be about 25 percent of 36 in., or about 9 in. Prior to May 20, 1993, there had been no 
rain for nearly two weeks (although $0.4 \mathrm{in}$. of rain had fallen on that date), so most of the 9 in. of moisture in the unsaturated zone was derived from the water table via capillary action.

Leakage from the surficial aquifer system to the Upper Floridan aquifer has been estimated as a result of modeling studies, and in the Talbot Terrace area leakance probably is in the range of $3 \times 10^{-5} / \mathrm{d}$ to $1 \times 10^{-4} / d$ (L.C. Murray, USGS, oral commun., 1995).
The average head difference between the surficial aquifer and the Upper Floridan aquifer at the well field was about $6 \mathrm{ft}$ for the period June 1992 through June 1994. This head difference, together with the leakance values, indicates a leakage from the surficial aquifer system of about 0.0002 to $0.0006 \mathrm{ft} / \mathrm{d}$. This leakage generally agrees with the optimized leakage of about $0.0008 \mathrm{ft} / \mathrm{d}$.

Table 2. Summary of optimization runs for wilt potential, extinction depth, leakage and field capacity, HW44 well field, June 20, 1992, through June 30, 1994

[Initial value patterns represent relative values of initial values for wilt potential, extinction depth, leakage, and field capacity. For example, HHHH indicates that the highest initial values of the three parameters were used in the optimization run. Exd, extinction depth, in feet; Fcap, field capacity, in percent of porosity; Wilt, wilt capacity, in percent of porosity; Rleak, leakage in feet per day. The root mean square error is the square root of the daily mean square difference between simulated and actual water table elevation]

\begin{tabular}{|c|c|c|c|c|c|c|c|c|c|}
\hline \multicolumn{5}{|c|}{ Initial value } & \multicolumn{4}{|c|}{ Optimized values } & \multirow{2}{*}{$\begin{array}{c}\text { Root mean } \\
\text { square } \\
\text { error } \\
\text { (feet) }\end{array}$} \\
\hline $\begin{array}{c}\text { Initial } \\
\text { value } \\
\text { pattern }\end{array}$ & Exd & Fcap & Wilt & Rleak & Exd & Fcap & Wilt & Rleak & \\
\hline НHНH & 8 & 0.9 & 0.7 & 0.01 & 0.051 & 0.79 & 0.70 & 0.0020 & 0.97 \\
\hline HHHL & 8 & .9 & .7 & .0002 & 1.50 & .88 & .70 & .00021 & .72 \\
\hline HHLH & 8 & .9 & .1 & .01 & .24 & .58 & .06 & .0020 & 1.04 \\
\hline HHLL & 8 & .9 & .1 & .0002 & 1.69 & .76 & .56 & .00033 & .69 \\
\hline HLHH & 8 & .1 & .7 & .01 & 3.69 & .70 & 69 & .00084 & .41 \\
\hline HLHL & 8 & .1 & .7 & .0002 & 5.58 & .25 & .24 &. .00005 & .67 \\
\hline HLLH & 8 & .1 & .1 & .01 & 3.53 & .29 & .29 & .0026 & .60 \\
\hline HLLL & 8 & .1 & .1 & .0002 & 5.58 & .15 & .14 & .00002 & .70 \\
\hline LHHH & 1 & .9 & .7 & .01 & .051 & .79 & .70 & .0020 & .97 \\
\hline LHHL & 1 & .9 & .7 & .0002 & 1.49 & .88 & .70 & .00020 & .73 \\
\hline LHLH & 1 & .9 & .1 & .01 & .22 & .58 & .06 & .0020 & 1.05 \\
\hline LHLL & 1 & .9 & .1 & .0002 & 1.40 & .81 & .57 & .00031 & .77 \\
\hline LLHH & 1 & .1 & .7 & .01 & 3.71 & .66 & .65 & .00082 & .42 \\
\hline LLHL & 1 & .1 & .7 & .0002 & 4.93 & .40 & .39 & .00009 & .57 \\
\hline LLLH & 1 & .1 & .1 & .01 & 3.69 & .29 & .29 & .0023 & .60 \\
\hline LLLL & 1 & .1 & .1 & .0002 & 3.69 & .29 & .29 & .0023 & .60 \\
\hline
\end{tabular}

The comparison between actual and simulated water levels at the HW44 well field indicates that the model generally is successful in predicting the major fluctuations of the water table, such as the major declines and recovery of the water table in JulyAugust 1992, and in March-July 1993 (fig. 9). The smaller-scale fluctuations in the water table are not accurately predicted. For example, several water-table rises, such as the one in October 1992 are not predicted at all. Some of this could be because rainfall at the gage may not represent the entire area represented by the well. For example, rainfall near enough to the well to affect the observed water table may not be measured at the site. Another area of mismatch between the model and the actual water levels is for periods where the water table is at or above land surface. The model uses a fixed elevation for land surface, whereas the well field, though flat in appearance, nevertheless has an irregular land surface. When the water table is at land surface at the observation well $(40.5 \mathrm{ft})$, it is actually above land surface in depressions and below land surface in other locations. 


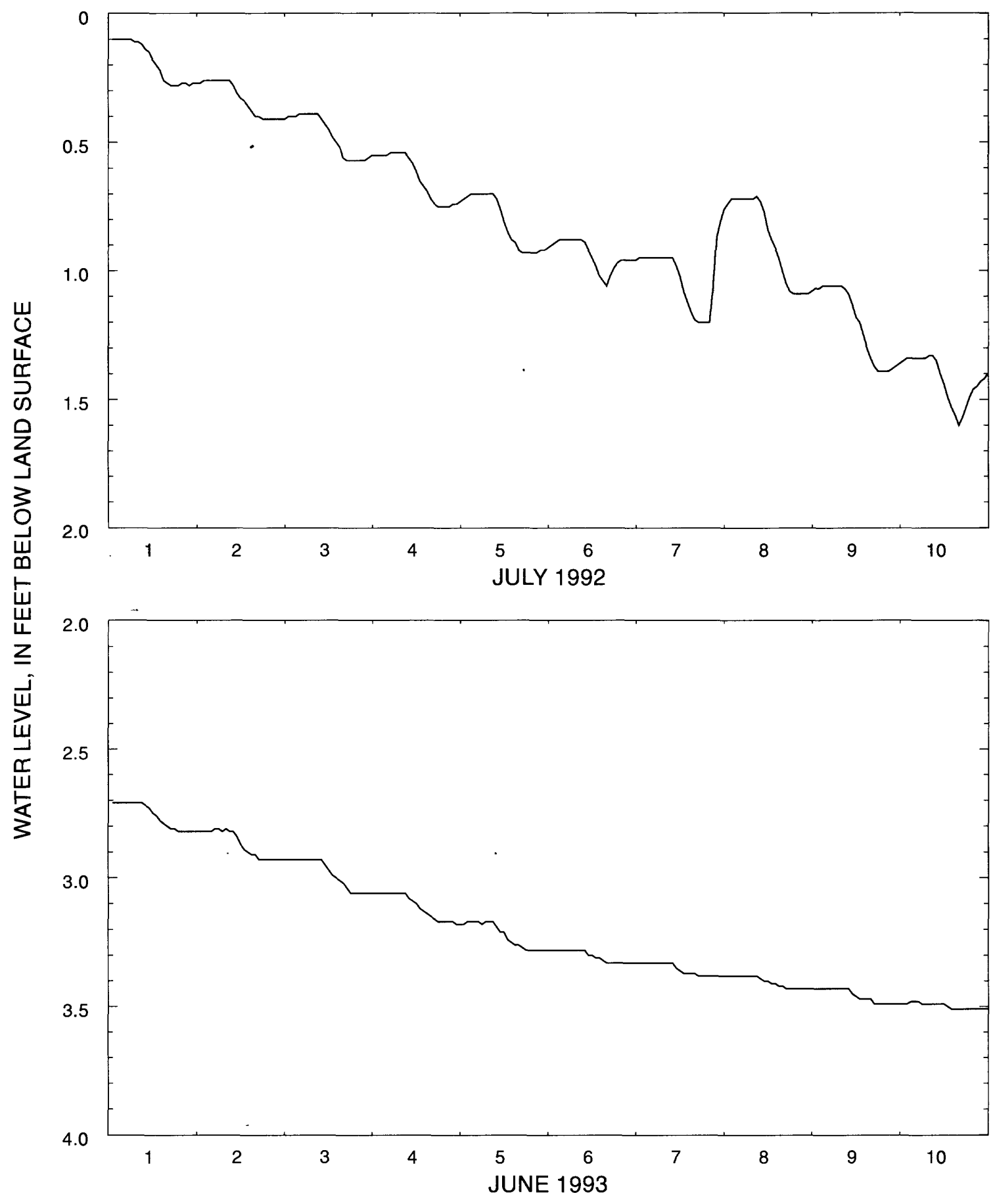

Figure 8. Hourly water level for 10-day periods beginning July 1, 1992, and June 1, 1993, at the HW44 well field. 


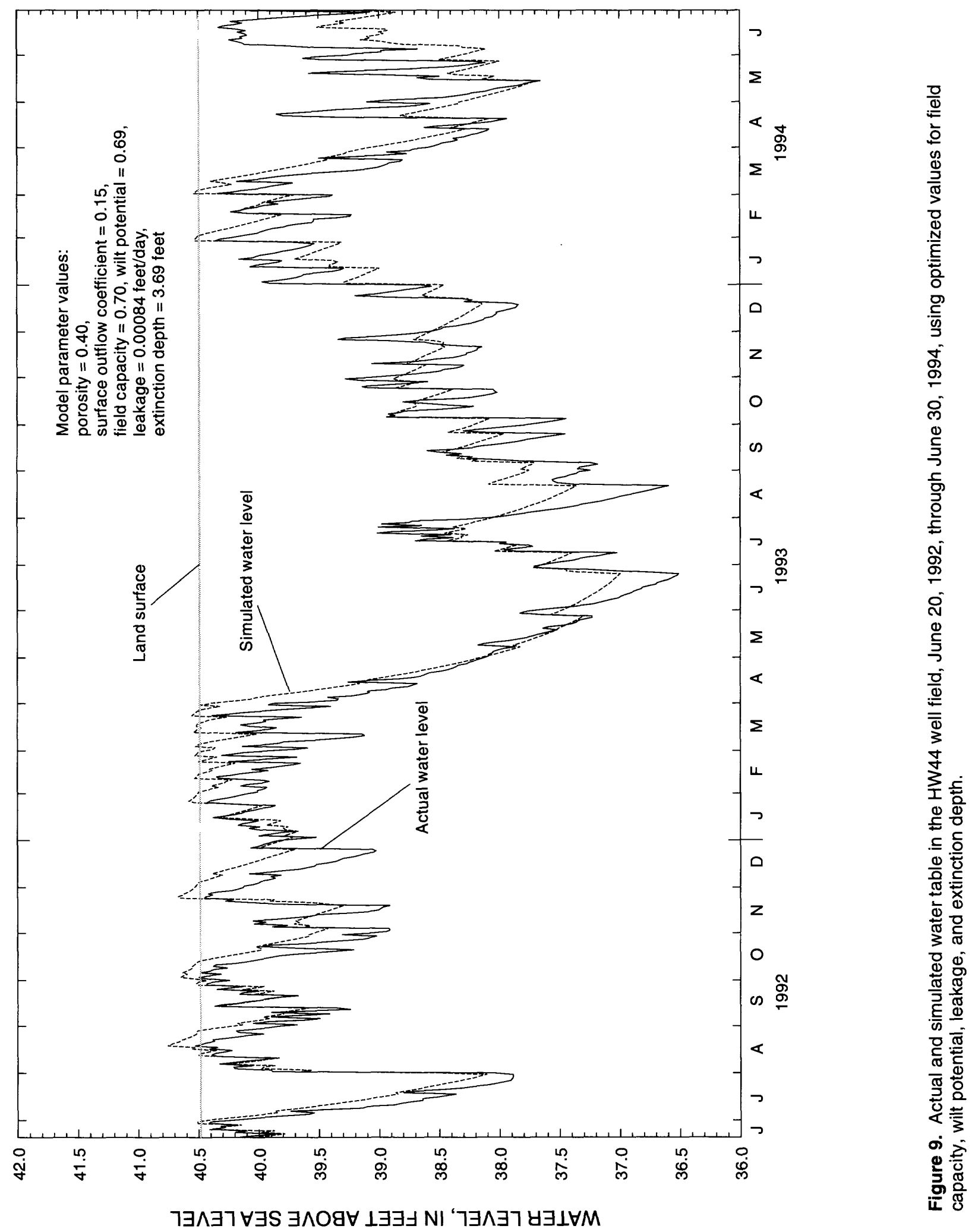


This irregularity makes runoff prediction inaccurate for small depths of water because the water level at the observation well does not represent the water level at other locations. Once the model has accumulated water on the land surface, it may take several days or weeks for proper tracking of the actual water level to resume. Thus, for the period in late November and December 1992, the simulated water level is always greater than the observed water level.

Comparison of cumulative-frequency distributions of actual and simulated water levels at the well field indicate that the model is almost always within 0.1 to $0.2 \mathrm{ft}$ of the actual water level with any selected frequency of occurrence (fig. 10). Median water levels are $39.13 \mathrm{ft}$ actual and $39.08 \mathrm{ft}$ above sea level simulated. The differences between simulated and actual are largest at the extremes: the minimum water level was $36.51 \mathrm{ft}$ actual and $36.82 \mathrm{ft}$ predicted, and the maximum water level was $40.53 \mathrm{ft}$ actual and $40.72 \mathrm{ft}$ predicted.

\section{Application of the Model to Simulate Flows for Two Streams in Volusia County}

A simple watershed model adequate to simulate surface outflow for some locations can be constructed using two-tank units that provide inflow to a third tank (fig. 11). The advantage of a two-tank conceptualization (over a single unit) is that it can represent a watershed with two areas that have different hydrologic characteristics. More tanks could be used if the basin were too complex to be represented by two tanks.

In the two-tank conceptualization, tanks 1 and 2 provide the runoff and the surface inflow to tank 3 (combined outflow from tanks 1 and 2) is the simulated streamflow. In this usage, tank 3 is defined with a land-surface elevation that is low in relation to that defined for tanks 1 and 2, so that no backwater effects are encountered. Tank 3 is, therefore, a "dummy" tank that does not have any effect on the simulated inflow and is defined only because the model needs to direct the simulated flow to some location-in this case, the tank 3 inflow.

Two small streams in wetland areas in central Florida were selected for modeling. One streamBlackwater Creek-is characterized by relatively uniform streamflow, and the other stream-Tiger Bay Canal-has more irregular streamflow. Together, the two probably represent the extremes in streamflow characteristics which can be seen from the dischargeduration curves for these and other streams (fig. 5).

The optimizer algorithm (Press and others, 1989) was used to find the best fit of three model parameters: $\mathrm{F}_{1.1}\left(F_{1}\right.$ from tank 1$), F_{1.2}\left(F_{1}\right.$ from tank 2 ), and the size of tank 1 . So that only a single size parameter would be necessary for the optimization procedure, tank sizes were defined such that the sum of tank 1 and tank 2 sizes equals 1 . This definition of relative tank sizes is analogous to the watershed consisting of two separate areas with different hydrologic characteristics--one area defined by tank 1 and the other area defined by tank 2 . The fit of observed and simulated discharges was made dimensionless by comparing daily values of percent of total runoff volume for the period of optimization, rather than actual discharges. A model parameter was eliminated from the optimization procedure by using dimensionless discharge because only relative sizes of the two tanks had to be specified, rather than the actual size of both tanks. To convert dimensionless discharges back to actual discharges, the dimensionless values of daily streamflow were multiplied by the ratio of total dimensionless runoff to the total observed discharge, in cubic feet per second, for the period of record.

Multiple optimization runs were made using all eight possible combinations of maximum and minimum initial parameter estimates for the three parameters. The results of the optimizer runs are given in table 3. Most of the optimizer runs finished with similar root mean square errors, in percent of total discharge volume, that ranged from .0474 to .0480 for Blackwater Creek and from .0377 to .0387 for Tiger Bay Canal. Because these errors were within a relatively small range, the set of optimized parameters that were chosen to best represent the stream were those that resulted in the smallest difference between the median simulated discharge and the median actual discharge. Best-fit selected values for Blackwater Creek were $F_{1.1}=0.00277, F_{1.2}=0.0707$, and relative size of tank $1=0.834$. Best-fit selected values for Tiger Bay Canal were $F_{1.1}=0.0142, F_{1.2}=0.107$, and relative size of tank $1=0.887$.

Comparison of the cumulative-frequency distributions of actual and simulated daily discharge indicates similar distributions (fig. 12). The fit for Blackwater Creek is somewhat better than the fit for Tiger Bay Canal, probably because it is easier to simulate a stream with uniform discharge characteristics than a stream with a greater fluctuation in streamflow. 


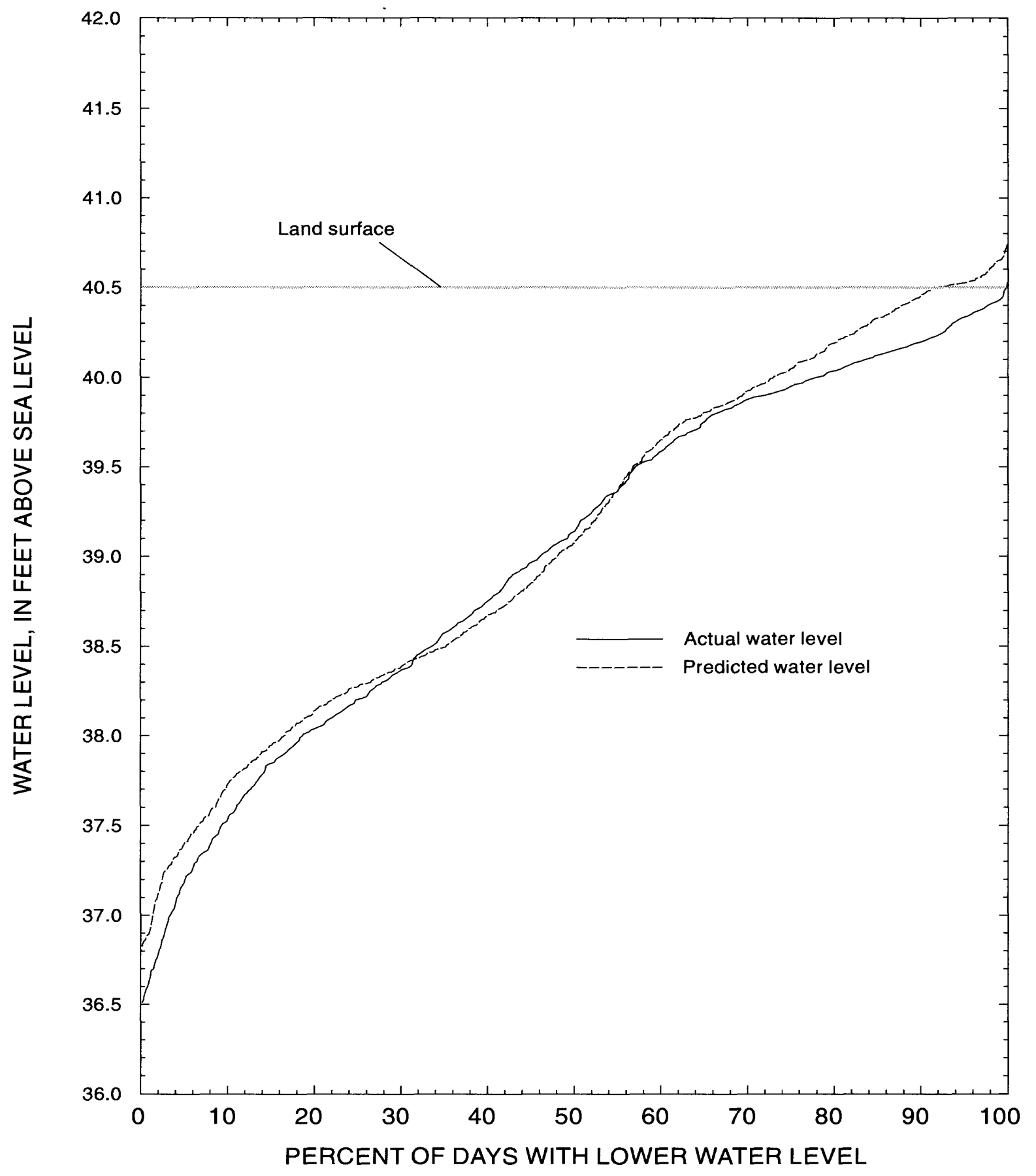

Figure 10. Cumulative frequency distribution of actual and simulated water levels at the HW44 well field, June 20, 1992, to June 30, 1994. 


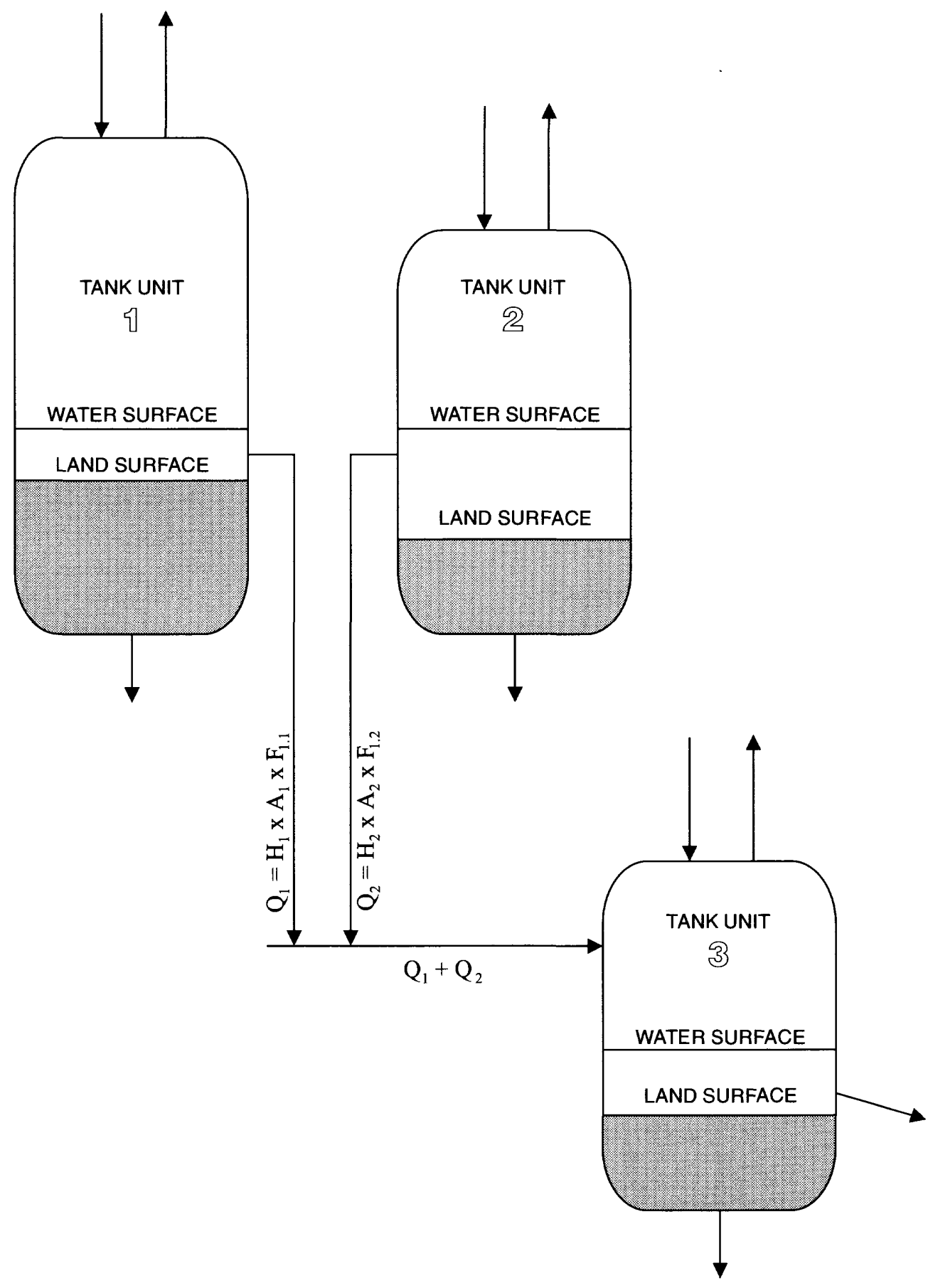

$\left(Q_{1}\right.$ and $\mathrm{Q}_{2}$ are the outflow rates, $\mathrm{H}_{1}$ and $\mathrm{H}_{2}$ are the depths of water above land surface, $\mathrm{A}_{1}$ and $\mathrm{A}_{2}$ are the cross-sectional areas, and $\mathrm{F}_{1.1}$ and $\mathrm{F}_{1.2}$ are the surface outflow rate constants.)

Figure 11. Diagram of a three-tank model used to simulate streamflow. 
Table 3. Summary of optimization runs for daily discharge of Blackwater Creek and Tiger Bay Canal

[Initial value patterns represent relative values of initial values for $F_{1.1}, F_{1.2}$, and relative size of tanks 1 and 2 - see figure 7 for diagram of conceptual model. For example, $\mathrm{HHH}$ indicates that the highest initial values of the three parameters were used in the optimization run. The error sum is the sum of the squares of the differences between actual and computed daily percent of total runoff. Daily discharge for the period October 1981 through September 1989 were used in the optimization]

\begin{tabular}{|c|c|c|c|c|c|c|c|}
\hline \multicolumn{4}{|c|}{ Initial value } & \multicolumn{3}{|c|}{ Optimized values } & \multirow{2}{*}{$\begin{array}{l}\text { Root mean } \\
\text { square } \\
\text { error } \\
\text { (dimen- } \\
\text { sionless } \\
\text { ratio) }\end{array}$} \\
\hline $\begin{array}{c}\text { Initial } \\
\text { value } \\
\text { pattern }\end{array}$ & $\mathbf{F}_{1.1}$ & $\mathbf{F}_{1.2}$ & $\begin{array}{c}\text { Relative } \\
\text { size, } \\
\text { tank } 1\end{array}$ & $\mathbf{F}_{1.1}$ & $\mathbf{F}_{1.2}$ & $\begin{array}{c}\text { Relative } \\
\text { size, } \\
\text { tank } 1\end{array}$ & \\
\hline \multicolumn{8}{|c|}{ Blackwater Creek } \\
\hline НHН & 0.8 & 0.8 & 0.95 & 0.00261 & 0.0978 & 0.860 & .0480 \\
\hline HHL & .8 & .8 & .05 & .0368 & .00245 & .225 & .0475 \\
\hline HLH & .8 & .05 & .95 & .00278 & .0736 & .838 & .0476 \\
\hline HLL & .8 & .05 & .05 & .0210 & .00183 & .329 & .0474 \\
\hline LHH & .05 & .8 & .95 & .00286 & .0710 & .836 & .0475 \\
\hline LHL & .05 & .8 & .05 & .0368 & .00245 & .225 & .0475 \\
\hline LLH & .05 & .05 & .95 & .00277 & .0707 & .834 & .0475 \\
\hline LLL & .05 & .05 & .05 & .0225 & .00194 & .313 & .0474 \\
\hline \multicolumn{8}{|c|}{ Tiger Bay Canal } \\
\hline $\mathrm{HHH}$ & .8 & .8 & .95 & 0.0141 & 0.103 & 0.880 & .0387 \\
\hline HHL & .8 & .8 & .05 & .00182 & .0220 & .420 & .0386 \\
\hline HLH & .8 & .05 & .95 & .0142 & .124 & .898 & .0387 \\
\hline HLL & .8 & .05 & .05 & .00180 & .0243 & .445 & .0386 \\
\hline LHH & .05 & .8 & .95 & .0142 & .107 & .887 & .0387 \\
\hline LHL & .05 & .8 & .05 & .0507 & .00434 & .330 & .0377 \\
\hline LLH & .05 & .05 & .95 & .0143 & .125 & .901 & .0387 \\
\hline LLL & .05 & .05 & .05 & .00178 & .0237 & .440 & .0386 \\
\hline
\end{tabular}

Comparison of the simulated and actual daily discharges was not as good as that for cumulativefrequency distributions (figs. 13 and 14). The simulated discharge hydrograph for Tiger Bay Canal (fig. 13) is somewhat smoother than the actual hydrograph, and indicates discharge during times when there was no streamflow. The simulated 1985 discharge peaks for Blackwater Creek are more sustained than was the actual discharge (fig. 14). This lack of fit probably is because the basins are too large to be adequately represented by a single rainfall station. (The drainage basins for Tiger Bay Canal and Blackwater Creek are 29 and 126 square miles $\left(\mathrm{mi}^{2}\right)$, respectively). The remaining lack of fit probably is because the model is too simple to accurately represent the basin. On a time scale of years, however, the single rainfall station may be representative of both basins, hence the relatively good fit between simulated and observed flow-duration curves. Thus, the models for these two streams might be used to set up models of conceptual wetlands that receive surface inflow.

\section{APPLICATION OF METHOD FOR CHARACTERIZING WATER LEVELS IN CONCEPTUAL WETLANDS}

The following section contains data regarding the model used to evaluate the sensitivity of simulated water levels to selected model variable values. The conceptual model used to simulate water levels in the HW44 well field was rerun with a range of selected values for extinction depth, soil-field capacity, wilt capacity, and surface inflow and outflow rates to perform sensitivity analyses. Additionally, two 


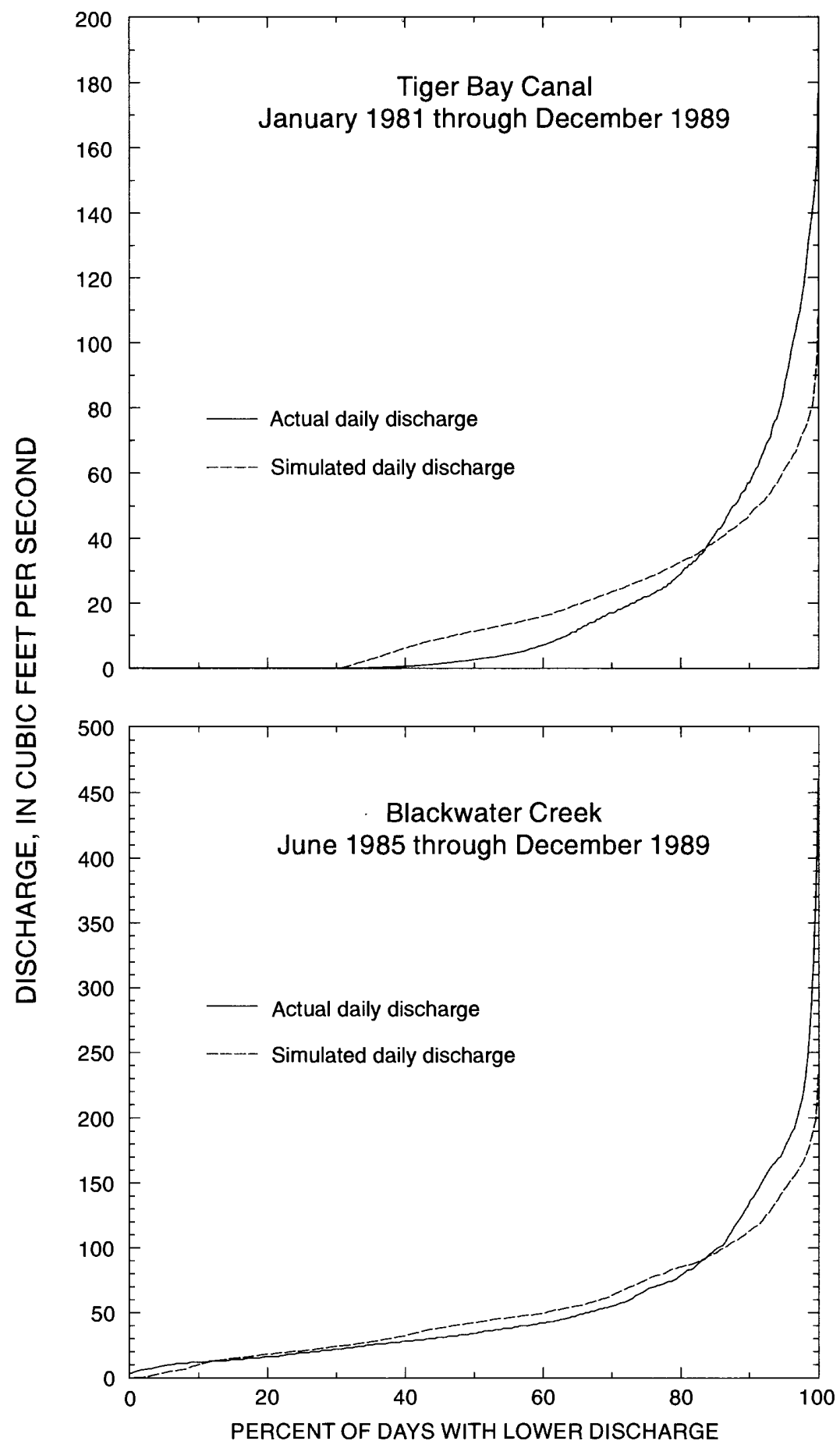

Figure 12. Cumulative-frequency distribution of simulated and observed daily discharge at Blackwater Creek and Tiger Bay Canal. 


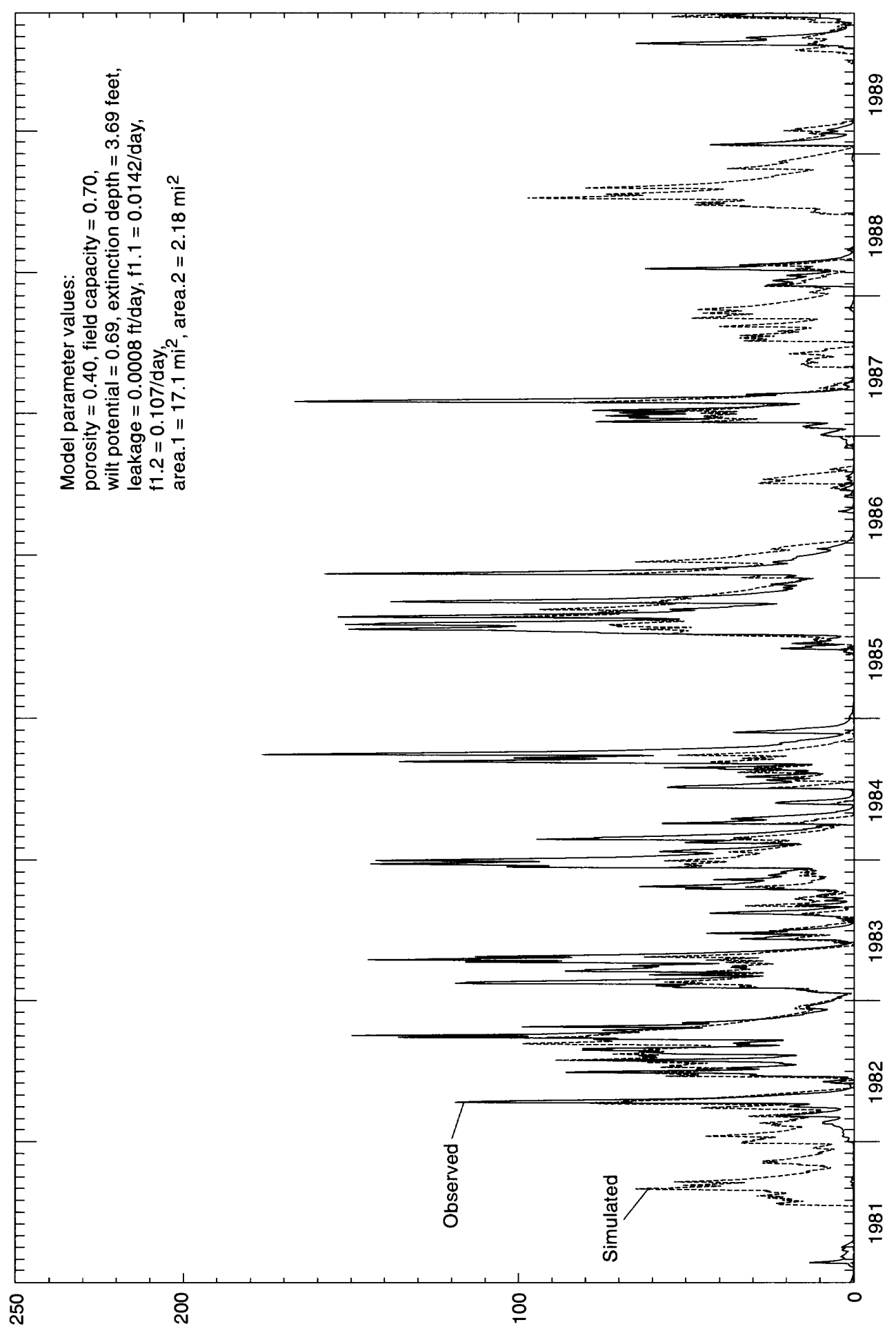

वNOO $\exists S$ U 


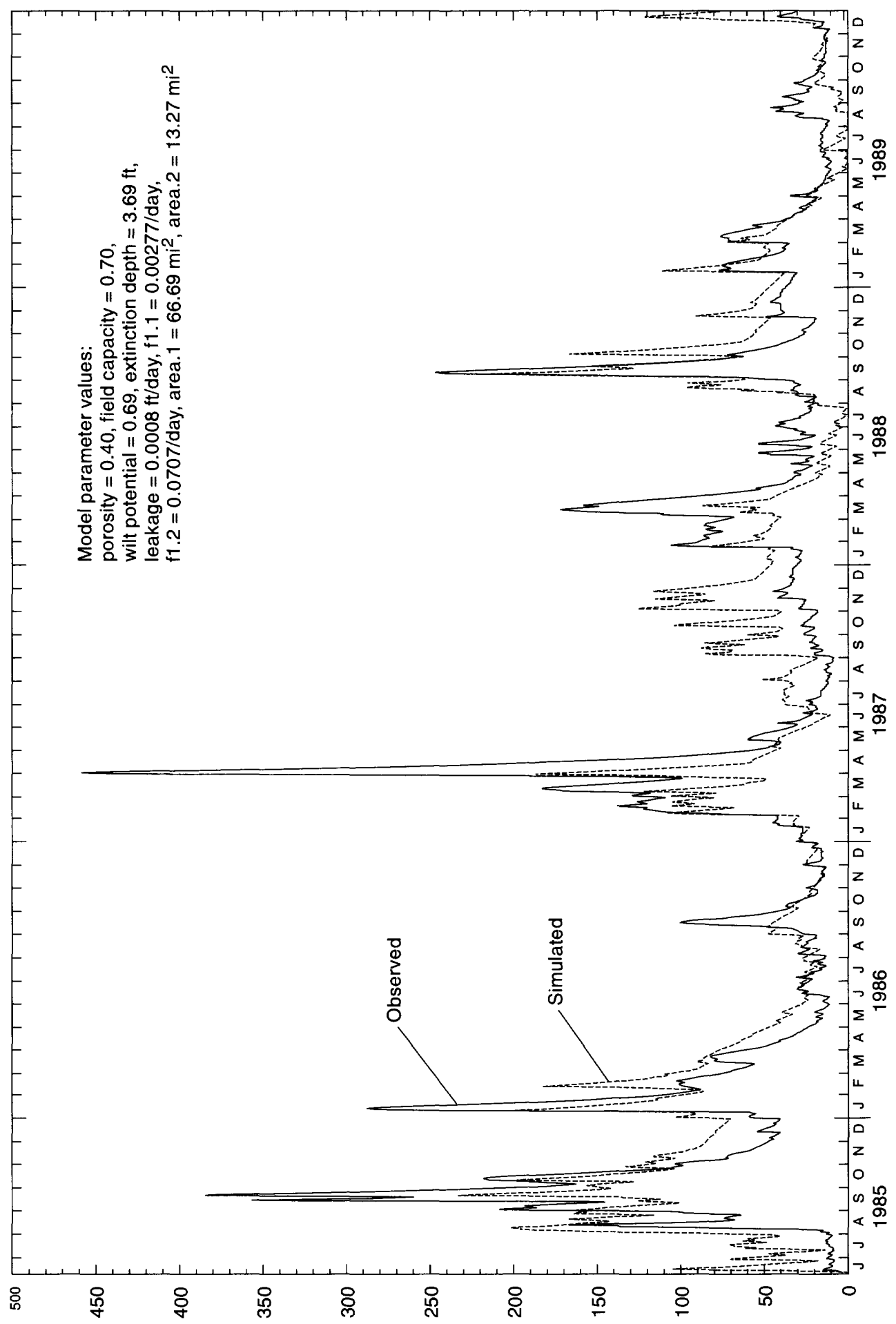

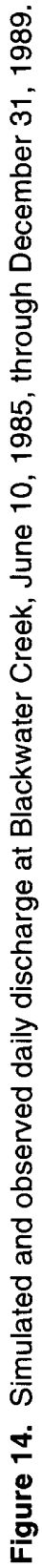

aNOว 
hypothetical cases are discussed in which examples of how the model was used to gain a general understanding of possible developmental impacts on wetland water levels. In all of these runs, a 59-year record of rainfall (January 1931 through December 1989) for the DeLand area was used (fig. 2).

The model described in this report uses a very simple conceptualization of wetlands hydrology. Models of much greater complexity, including extensive descriptive information about the watershed being modeled, would make more accurate simulations of water levels in actual wetlands. The intended purpose of the model described here is to give users a tool to understand wetlands hydrology in a semi-quantitative way and to determine relative sensitivity of a system to developmental impacts.

\section{Sensitivity of Simulated Water Levels to Selected Model Parameters}

The value chosen for extinction depth affects simulated water levels. A greater extinction depth allows ET to penetrate deeper into the soil which results in lower water levels as compared to lesser extinction depths (fig. 15). The effect is most notable at the low end of the stage-duration curves. Minimum simulated water levels ranged from about $6.7 \mathrm{ft}$ below land surface (using an extinction depth of $8 \mathrm{ft}$ ) to about $2.5 \mathrm{ft}$ below land surface (using a 2-ft extinction depth). Maximum simulated water levels were not affected by the extinction depth. Hydroperiods ranged from about 20 percent for a 2 -ft extinction depth to about 10 percent for a 8 -ft extinction depth. These simulations indicate that wetlands containing deeply rooted plants may tend to be drier than those with grasses or other shallow-rooted plants.

The ability of the soil to hold moisture affects the simulated water levels but does not affect the hydroperiod (fig. 16). Simulated water levels are lowest in soils with a high capacity for moisture; that is, for soils with a high field capacity and a low wilt potential. In such soils, ET is enhanced because relatively large quantities of water are held nearer the land surface. The greater the depth of water below land surface, the more pronounced the effect of soil-moisture storage. For example, the minimum simulated water level in soil with almost no moisture storage capacity (field capacity $=1$ percent of porosity, wilt potential $=0$ percent of porosity) is about $3.6 \mathrm{ft}$ below land surface, whereas the minimum simulated water level in soil with the most storage capacity (field capacity $=60$ percent, wilt potential $=0$ percent ) is about $5.7 \mathrm{ft}$ below the land surface. The effect of soil storage is not as pronounced near land surface and the duration of simulated water levels above land surface is nearly the same regardless of soil moisture storage.

The effect of stream-inflow characteristics on simulated water levels in a wetland is shown by the comparison of water-level duration curves for a wetland fed by streams with different streamflow characteristics (fig. 17). In this comparison, the models for Tiger Bay Canal, with an irregular duration (fig. 13), and Blackwater Creek, with a relatively uniform streamflow duration (fig. 14), were used to represent a range of surfaceinflow characteristics. In both cases, the ratio of drainage area to wetlands was set at 30 . There are two major differences between the two water-level duration curves; the curve generated using the Blackwater Creek flow characteristics shows a less variable water level, and a longer hydroperiod than the other curve. The simulated water surfaces generated using the more flashy Tiger Bay Canal flow characteristics ranged from -3.4 to $4.5 \mathrm{ft}$ above land surface with a hydroperiod of about 60 percent, and the surface generated using the Blackwater Creek flow characteristics ranged only from -2.6 to $1.6 \mathrm{ft}$ above land surface, with a hydroperiod of about 88 percent. The effect of the different inflow characteristics is least near the midpoint of the water-level duration curve and the median water levels simulated by the two inflows differed only by about $0.1 \mathrm{ft}$.

\section{Examples of Estimating Wetlands Response to Hydrologic Stresses}

The use of the model described in this report is demonstrated by the following two hypothetical cases. One case is an assessment of the relative sensitivity of wetland water levels to increased leakage from the surficial aquifer system to the Upper Floridan aquifer caused by withdrawal of water from the Floridan aquifer. The other case is an assessment of the effects of altering the size of a surface-water drainage basin. Although the model yields specific outcomes for water levels and hydroperiods, the relations used in the model represent only simple and idealized conceptualizations of wetlands hydrology and are in no way intended to be accurate representations of any actual system. The model is only intended to give users a general feel for the sensitivity of wetland water levels to the effects from developmental impacts. 


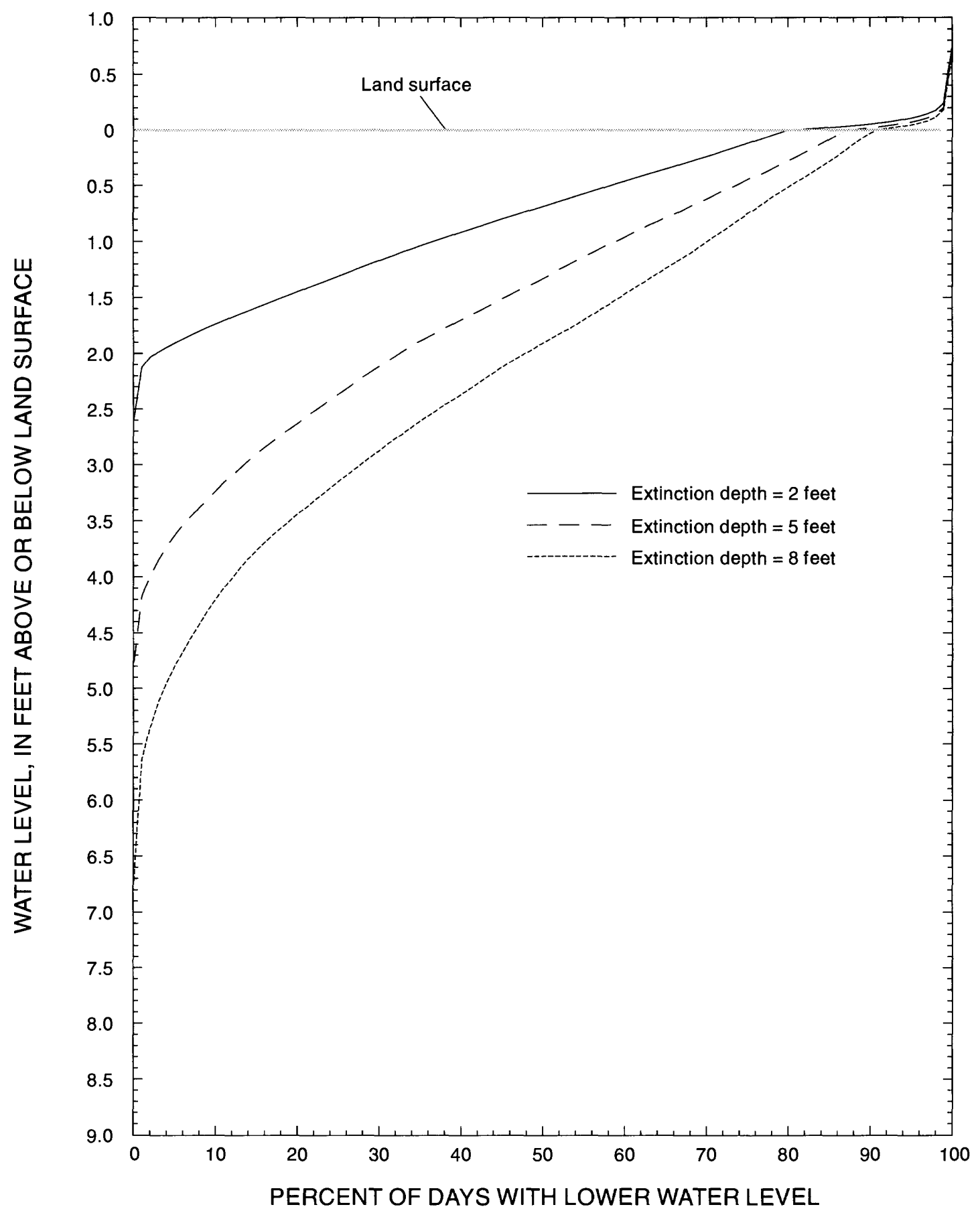

Figure 15. The effect of extinction depth on simulated water levels, HW44 well-field model. 


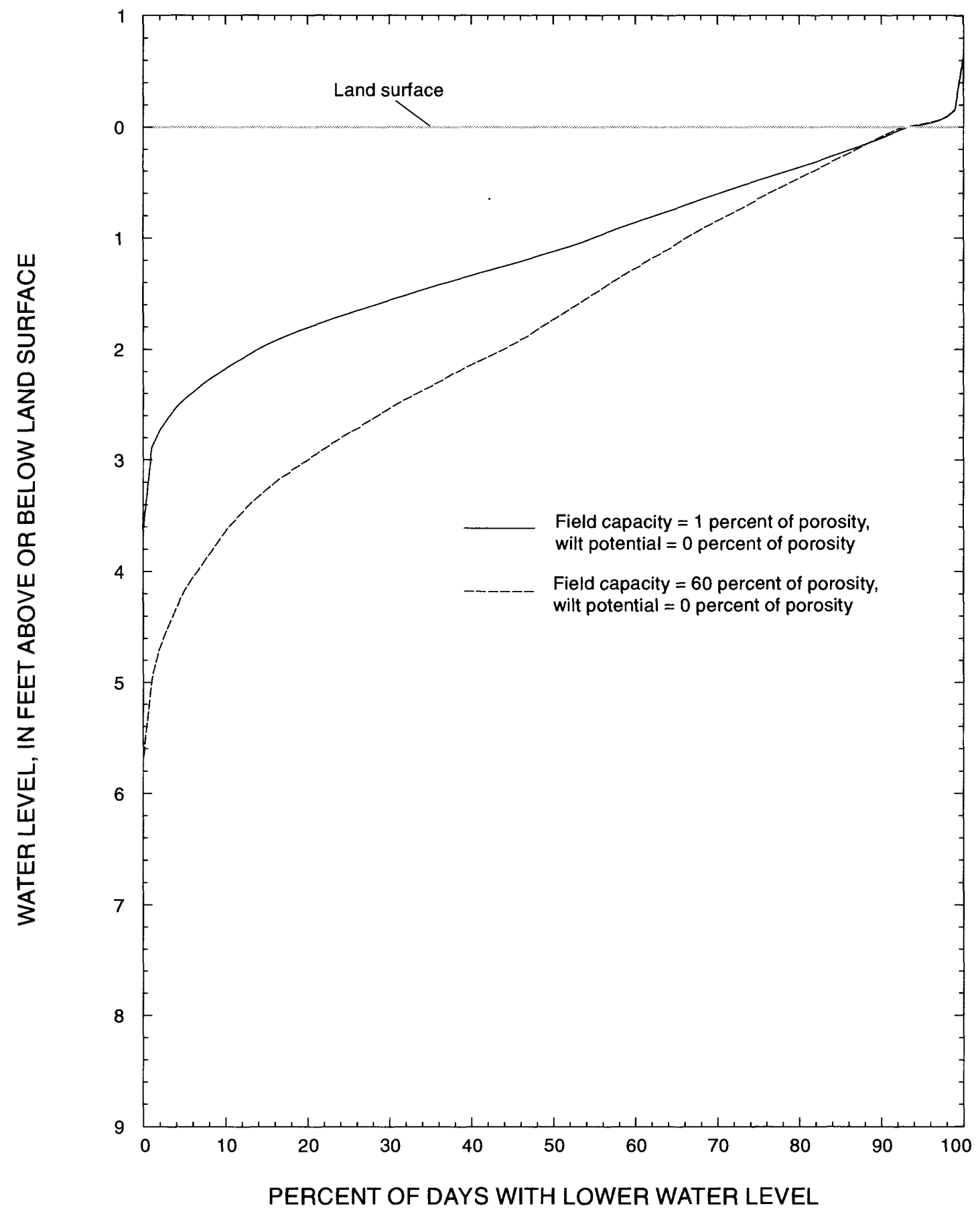

Figure 16. The effect of field capacity and wilt potential on simulated water levels, HW44 well-field model. 


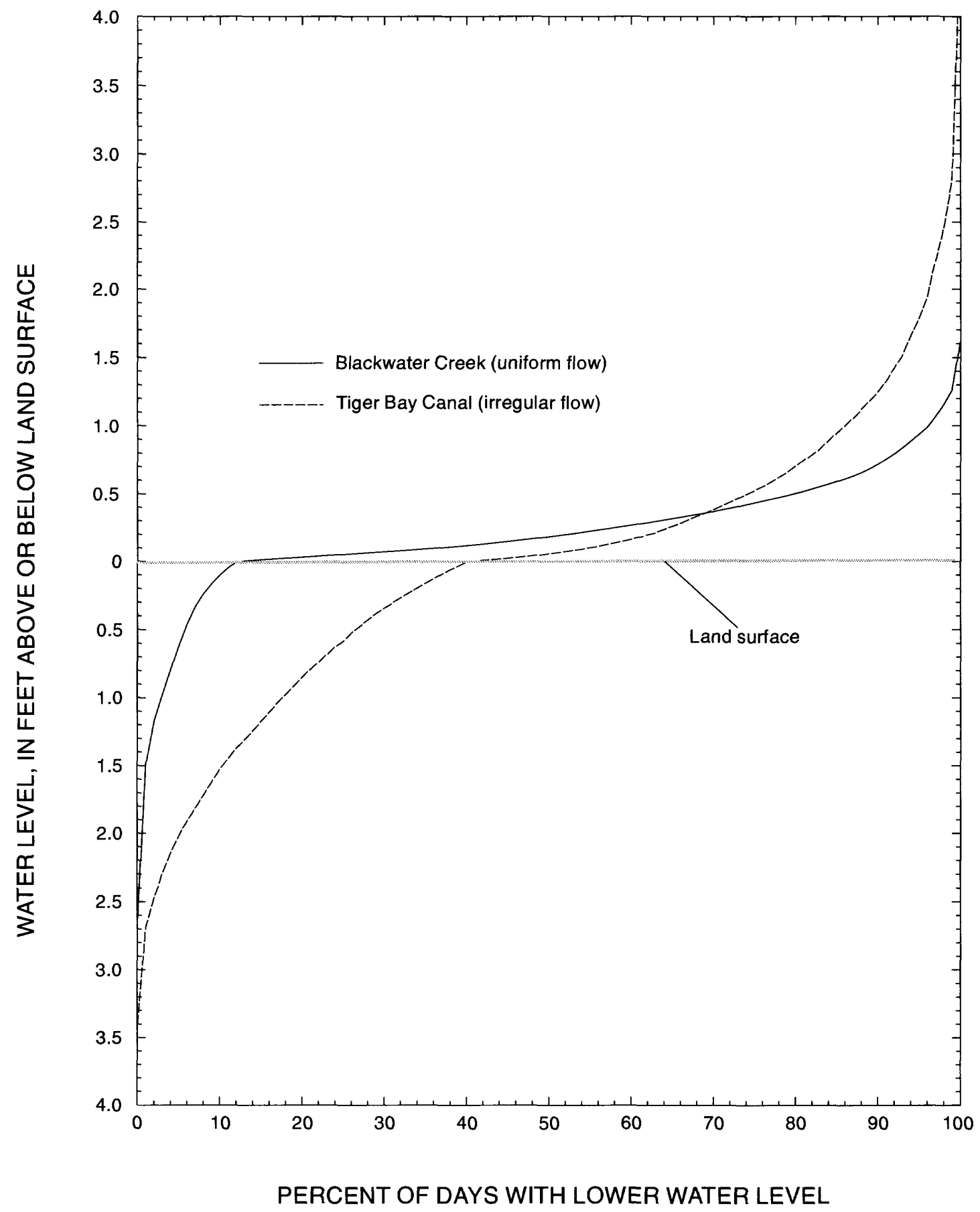

Figure 17. The effect of surface-inflow duration characteristics on simulated water levels, HW44 wellfield model. 
Hypothetical Case 1: Effect of Withdrawal of Water from the Upper Floridan Aquifer on Water Levels in an Isolated Wetland

In this case, the effects of lowering the potentiometric surface of the Floridan aquifer system on water levels in an isolated wetland are considered. The hypothetical wetland only receives water from direct precipitation and loses water to ET, surface runoff, and leakage to the Floridan aquifer system. Two cases are considered here: a slowly draining wetland where the time to remove half the surface storage is about 14 days $\left(F_{1}=0.05\right)$, and a rapidly draining wetland, where the time to remove half the surface storage is about 2.5 days $\left(F_{l}=0.30\right)$.

The hypothetical wetland considered here is designed to resemble the HW44 well field in Volusia County. Surface inflow probably can be neglected except during periods of high water levels. Subsurface inflow is not considered in the model and probably is not an important component of flow at the well-field site because of the absence of higher areas near the well field. By neglecting subsurface inflow, the reductions in water levels related to drawdown in the Upper Floridan aquifer predicted by this model can be considered "worst-case" predictions. Any inflow of water induced by lowering the water table in the well field will mitigate the effects of pumping.

In this example, the effect of a $10-\mathrm{ft}$ increase in the head difference between the surficial aquifer system and the Upper Floridan aquifer over the entire area of concern is evaluated. A uniform lowering of the potentiometric surface does not occur in an actual well field because the actual potentiometric surface is the result of overlapping cones of depression around each well. Also, to avoid excessive drawdowns in any one well, the total pumpage from the well field may be rotated on a daily basis among several wells. Thus, depending on the schedule of pumping, the potentiometric surface may vary significantly between nearby points, and selected locations may vary by relatively large amounts on a daily basis. These considerations cannot be included with the simple concepts presented here. However, a generalized assessment of the sensitivity of the area to pumpage may be made.

A single tank unit (fig. 6) is used as the conceptual model of the well field. An evaluation of the effects of pumping was made by running the model twice, first using a leakage rate assumed to have occurred before the start of pumpage, and second by using an increased leakage rate assumed to result from an increase in the gradient between the surficial aquifer system and the Upper Floridan aquifer. In both cases, the rainfall used in the simulation is the 59-year daily record for the DeLand area (fig. 2). Parameter values used in both of the simulations are: pore, 0.40 ; fcap, 0.70; wilt, 0.69; and exd, 3.69. These are the values used for the best fit of the HW44 well-field water levels for June 1992 through June 1994 (fig. 9). The leakage used for the before-pumping simulation is the optimized value of $0.00084 \mathrm{ft} / \mathrm{d}$ (3.7 inches per year (in/yr)).

The new leakage values used for simulating the after-start-up case were estimated from the specified increase in gradient between the water table and the Upper Floridan aquifer. The before-pumpage gradient was estimated from data for the period June 1992 through June 1994, when the average elevation of the water table was $38.5 \mathrm{ft}$ above sea level and the average potentiometric level in the Upper Floridan aquifer was $32.4 \mathrm{ft}$, giving a mean difference in head of about $6 \mathrm{ft}$ between the surficial aquifer system and the Upper Floridan aquifer. Therefore, the specification of the new gradient of $16 \mathrm{ft}$ would increase leakage, at least initially, by $16 / 6$, or by a factor of about 2.7 . Thus the new leakage would be about $0.00227 \mathrm{ft} / \mathrm{d}$ (about $10 \mathrm{in} / \mathrm{yr}$ ).

The stage-duration curves for the selected leakage rates are given in figure 18 and effects of the hypothetical increase in downward leakage are summarized in the following table:

\begin{tabular}{|c|c|c|}
\hline & Fast draining & Slow draining \\
\hline & \multicolumn{2}{|c|}{ Water level, in feet above land surface } \\
\hline \multicolumn{3}{|l|}{ Minimum } \\
\hline Before pumping & -3.6 & -3.6 \\
\hline After pumping & -4.5 & -4.3 \\
\hline \multicolumn{3}{|l|}{ Median } \\
\hline Before pumping & -1 & -0.5 \\
\hline After pumping & -1.4 & -1.1 \\
\hline \multicolumn{3}{|l|}{ Maximum } \\
\hline Before pumping & 6 & 0.8 \\
\hline After pumping & 6 & .8 \\
\hline \multicolumn{3}{|c|}{ Water level, in percent of days above land surface } \\
\hline \multicolumn{3}{|l|}{ Hydroperiod } \\
\hline Before pumping & 16 & 35 \\
\hline After pumping & 11 & 25 \\
\hline
\end{tabular}

According to this hypothetical case, the increased head difference of $10 \mathrm{ft}$ would lower minimum water levels by about $1 \mathrm{ft}$. Median water levels would be lowered about $0.5 \mathrm{ft}$ and the maximum water levels would be nearly unaffected by the pumping.

It should be emphasized that these estimated changes are gross hypothetical estimates and could be over-predicted. The inflow of water from the surficial 


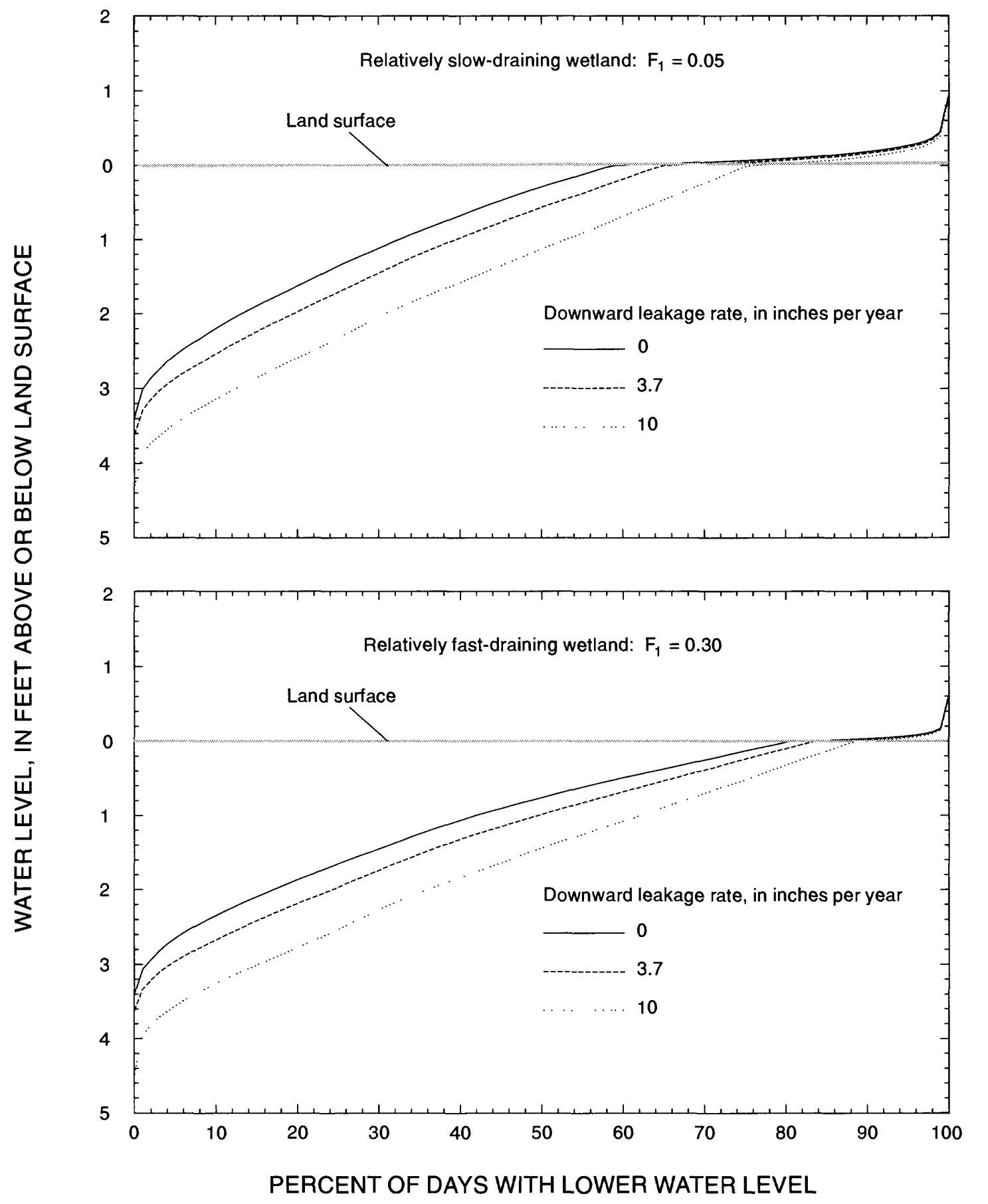

Figure 18. Stage duration in a hypothetical wetlands with no surface inflow, for selected downwardleakage rates and surface-drainage rates. 
aquifer from adjacent areas not affected by the drawdown could help to mitigate water-table lowering in the area of pumpage.

The model can approximate the magnitude of possible water-table declines resulting from various types of development. However, ecological effects on the area are much more difficult to assess. The change in head difference in this example actually would affect the water level in a subtle way in relation to yearly variation in rainfall and water level. Even if pre-and-post change water-level records were available, it could require many years of water-level record to discern a 0.5 - $\mathrm{ft}$ drop in the median elevation of the water table. Under the hypothetical stressed conditions described here, the water table would still rise above land surface occasionally and a casual observer might not notice any effects. The effect of small changes in water levels on plant communities would be difficult to predict because there could be no reaction for many years, especially if the decline in water level were offset by a series of wetter-thannormal years.

\section{Hypothetical Case 2: Effect of Alteration of Wetlands Drainage-Basin Size}

In this case, the effect of reducing the drainage area of a stream feeding a wetland is considered. The hypothetical wetland receives water from direct precipitation and from streamflow with a drainage area defined by the drainage area/wetlands area ratio. The wetland loses water to ET, surface runoff, and downward leakage to the Floridan aquifer system. Two cases are considered here: a slowly draining wetland where the time to remove half of the surface storage is about 14 days, and a rapidly draining wetland where the time to remove half of the surface storage is about 2.5 days. For both cases, the effects of reducing the drainage area by a factor of 2 are considered.

For this example, the hypothetical wetland is the same as that used in the previous example, except that it receives inflow from a stream. The model is set up as shown in figure 11 , where the runoff coefficients $F_{1.1}$ and $F_{1.2}$ and the relative sizes of tanks 1 and 3 are selected to produce discharge with a dischargeduration curve resembling the curve for Tiger Bay Canal (fig. 12). The simulated wetland is represented by tank $3 . F_{1.3}$ represents the surface outflow rate.
The "before-alteration" drainage area/wetlands area ratio is selected to be 10 , and the "after-alteration" ratio is selected to be 5 .

The stage-duration curves for the selected drainage area/wetlands area ratios are given in figure 19 and effects of the hypothetical decrease in drainage ratio are summarized in the following table:

\begin{tabular}{|c|c|c|}
\hline & Fast draining & Slow draining \\
\hline & \multicolumn{2}{|c|}{ Water level, in feet above land surface } \\
\hline \multicolumn{3}{|l|}{ Minimum } \\
\hline Before alteration & -3.6 & -3.6 \\
\hline After alteration & -3.6 & -3.6 \\
\hline \multicolumn{3}{|l|}{ Median } \\
\hline Before alteration & 0.0 & 0.14 \\
\hline After alteration & -0.2 & 0.10 \\
\hline \multicolumn{3}{|l|}{ Maximum } \\
\hline Before alteration & 1.0 & 3.3 \\
\hline After alteration & 0.9 & 1.9 \\
\hline \multicolumn{3}{|c|}{ Water level, in percent of days above land surface } \\
\hline \multicolumn{3}{|c|}{ Hydroperiod } \\
\hline Before alteration & 50 & 63 \\
\hline After alteration & 44 & 58 \\
\hline
\end{tabular}

There is no noticeable effect from the reduction in drainage area on minimum water levels - the hypothetical minimum water levels are about $4 \mathrm{ft}$ below land surface both before and after the alteration. Median water levels are lowered about $0.2 \mathrm{ft}$ or less by the alteration. Maximum water levels are affected the most (more than $1 \mathrm{ft}$ lower), but are relatively unchanged in the case of the fast-draining wetland. Hydroperiods are reduced slightly in both the slowand fast-draining wetland cases.

As previously discussed, the magnitude of these hypothetical changes probably is small in relation to the year-to-year differences in climatic conditions and water levels. Thus, many years of record and careful analysis of before-and-after change water-level record would be required to detect the changes. . 


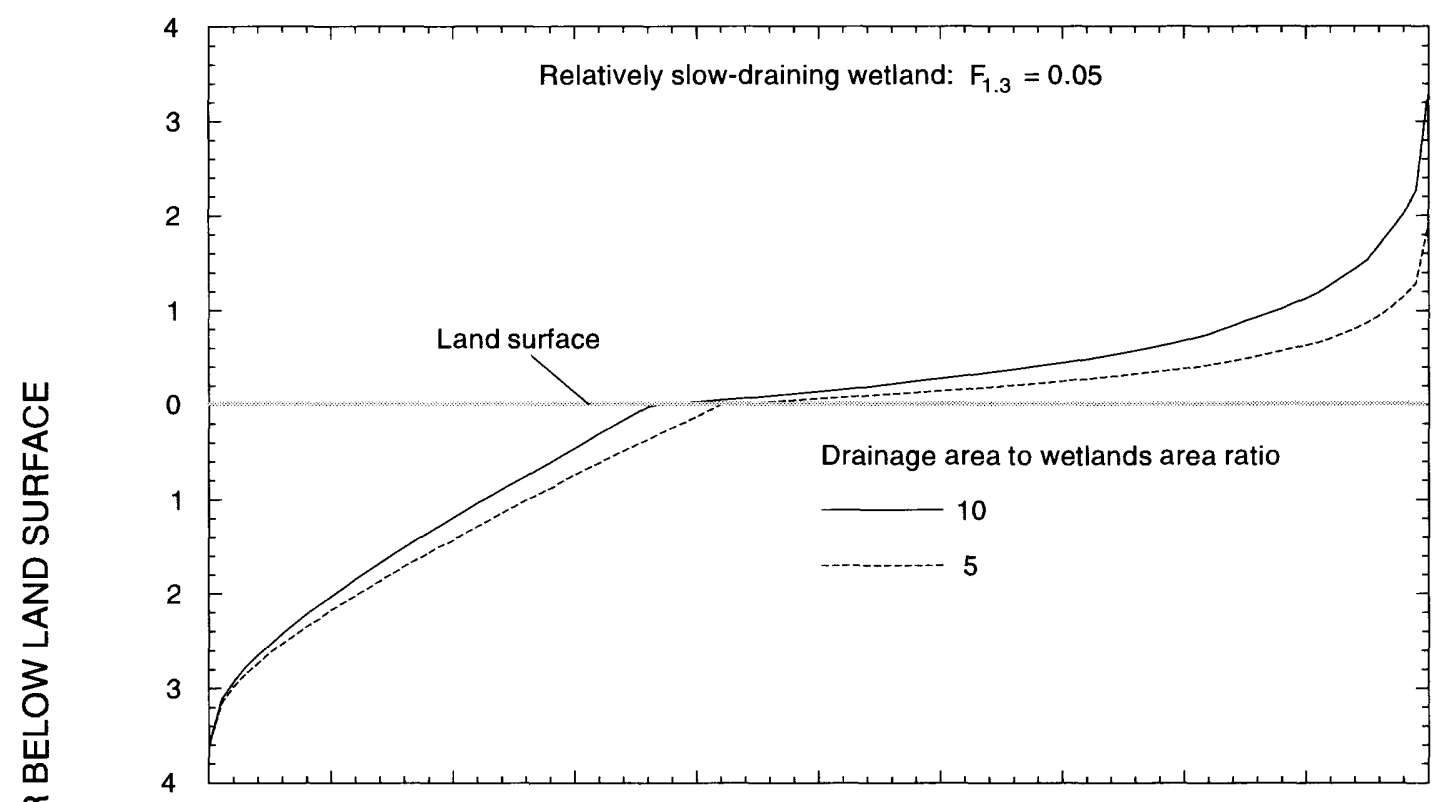

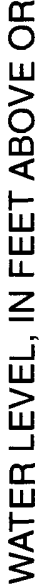

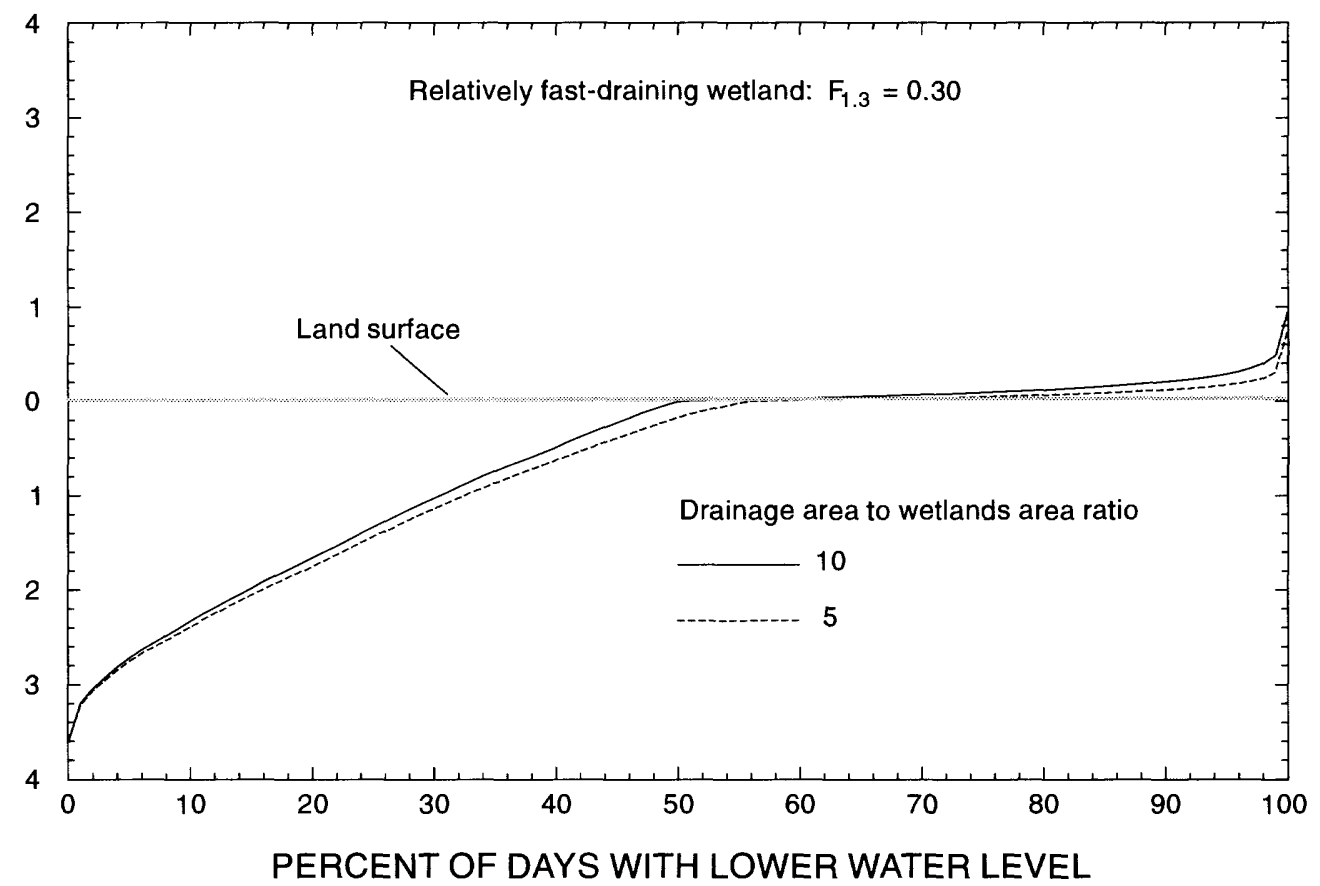

(A three-tank model simulating flow-duration characteristics of Tiger-Bay Canal was used to simulate the surface inflow.)

Figure 19. Stage duration in a hypothetical wetlands with selected wetlands area to drainage area ratios. 


\section{SUMMARY AND CONCLUSIONS}

A simple water-budget model was developed as a tool to assess the effects of developmental impacts on water levels in wetlands. The model is designed so that a hypothetical hydrologic system can be simulated as a series of tanks. Outflow from one tank can be directed into another tank, linking the tanks together as desired. Simulated water levels in the tanks can be output to a file for plotting or other data analysis.

The model was evaluated by applying it to a wetland area in Volusia County, Florida, known as the HW44 well field, for June 1992 through June 1994. This is an isolated wetland that is not part of a well-defined stream system. An optimizer routine was used to determine the values for selected model variables that resulted in the best fit between observed and simulated water table. Comparison of the cumulative-frequency distribution of actual and simulated water levels indicates that the simulated water table at the well field was almost always within 0.1 to 0.2 foot $(\mathrm{ft})$ of the actual water table at any selected frequency of occurrence. The median simulated water table for the period was $39.08 \mathrm{ft}$ above sea level and the median actual water table was $39.13 \mathrm{ft}$.

The model also was used to simulate daily surface discharge from two small streams in the central Florida area. An optimizer routine was used to determine the values for model parameters that resulted in the best match between daily simulated and actual relative discharge. The relative discharge for each day is the daily discharge in percent of the total runoff volume for the period of simulation. Two streams with different streamflow duration characteristics (Blackwater Creek and Tiger Bay Canal) were selected to represent the range in the types of streams feeding wetlands in the central Florida area. The simulated daily discharges were distributed much like the actual discharges, especially for Blackwater Creek, which has a much more uniform streamflow distribution than Tiger Bay Canal. Comparison of the simulated and actual daily discharges was not as good as that for cumulative-frequency distributions. Part of the disagreement between simulated and observed daily discharge may result from the fact that the rainfall record was for a single station and may not have been representative of the entire stream basin on a daily basis. On a time scale of years, however, the single rainfall station may be representative of both basins, hence the relatively good fit between simulated and observed flow-duration curves. Thus the models for these two streams might be used to set up models of conceptual wetlands that receive surface inflow.

A series of model runs was made to assess the sensitivity of simulated water levels to the values of selected model parameters. The sensitivity assessment was made using the model of the HW44 well field as a test case, and simulating water levels for a 59-year period (1931-89). The sensitivity assessment was done for extraction depth, soil moisture-holding ability, and stream-inflow characteristics.

Two hypothetical cases were simulated to determine the effects of developmental impact on wetlands water levels. These cases demonstrate the way in which the model might be used to gain a general understanding of possible developmental effects.

In the first simulation, the effect of lowering the potentiometric surface of the Floridan aquifer system on water levels in an isolated wetland was considered. In this case, the effect of increasing the head difference between the surficial aquifer system and the Upper Floridan aquifer by $10 \mathrm{ft}$ over the entire wetland was evaluated. According to this hypothetical case, the increased head difference of $10 \mathrm{ft}$ would lower minimum water levels by about $1 \mathrm{ft}$. Median water levels would be lowered about $0.5 \mathrm{ft}$ and the maximum water levels would be nearly unaffected.

In the second simulation, the effect of reducing the drainage area of a stream feeding a wetland is considered. The hypothetical wetland receives water from direct precipitation and from streamflow with a drainage area/wetlands area ratio of 10 . In this case, the effects of reducing the drainage area by a factor of 2 are considered.

There was no noticeable effect of the reduction in drainage area on minimum water levels-the hypothetical minimum water levels were about $4 \mathrm{ft}$ below land surface both before and after the hypothetical alteration. Median water levels were lowered $0.2 \mathrm{ft}$ or less by the alteration. Maximum water levels were affected the most (more than $1 \mathrm{ft}$ lower), and hydroperiods were slightly reduced.

The model can give some indication of the magnitude of water-table changes that might result from various types of development. However, effects on the ecology of the area are much more difficult to assess. In many cases, any changes would affect the 
water level in a subtle way in relation to year-to-year variation in rainfall and water level. Even if preand-post change water-level records were available, it could require many years of record to detect a small change in the elevation of the water table. Even under stressed conditions that could act to lower the water table, the water table would still occasionally rise above land surface and a casual observer might not detect any effects. The effects of small changes in water levels on plant communities would be difficult to predict because there would be no reaction for many years, especially if a decline in water level were offset by a series of wetter-than-normal years.

It should be emphasized that the model described in this report uses a very simple conceptualization of wetlands hydrology. Models of much greater complexity, including extensive descriptive information about the watershed being modeled, would be required to make accurate simulations of water levels in actual wetlands. The intended purpose of the model described here is to give users a tool to understand wetlands hydrology in a semi-quantitative way and to determine relative sensitivity of a system to developmental impacts.

\section{SELECTED REFERENCES}

Chow, V.T., 1964, Handbook of applied hydrology: New York, Mcgraw-Hill, 29 sections.

Cooke, C.W., 1945, Geology of Florida: Tallahassee, Florida Geological Survey, Geological Bulletin No. 29, 339 p.

Hall, C.A.S., and Day, J.W., eds., 1977, Ecosystem modeling in theory and practice: New York, John Wiley, $684 \mathrm{p}$.

Kohler, M.A., 1954, Lake and pan evaporation, in Waterloss investigations: Lake Hefner studies, technical report: U.S. Geological Survey Professional Paper 269, p. 127-148.

Murray, L.C., Jr., and Halford, K.J., 1996, Hydrologic conditions and simulation of ground-water flow in the greater Orlando metropolitan area, east-central Florida: U.S. Geological Survey Water-Resources Investigations Report 96-4181, $100 \mathrm{p}$.

Nofziger, D.L., and Hornsby, A.G., 1985, Chemical movement in soil: IBM PC User's Guide: Institute of Food and Agricultural Science, University of Florida Circular 654, $58 \mathrm{p}$.

Novotny, V., and Olem, H., 1994, Water quality: prevention, identification, and management of diffuse pollution: New York, Van Nostrand Reinhold, 1054 p.
Press, W.H., Flannery, B.P., Teukolsky, S.A., and Vetterling, W.T., 1989, Numerical recipes --The art of scientific computing (Fortran Version):Cambridge, Cambridge University Press, 702 p.

Tibbals, C.H., 1990, Hydrology of the Floridan aquifer system in east-central Florida: U.S. Geological Survey Professional Paper 1403-E, 98 p.

Todd, D.K., 1980, Groundwater hydrology: New York, John Wiley, p. 26. 
APPENDIXES 
38 A Method for Evaluating Water-Level Response to Hydrologic Stresses in Karstic Wetlands in Central Florida, Using a Simple Water-Balance Model 


\section{Appendix I - Representative soil characteristics for some central Florida areas}

The following values of total porosity are taken from Todd (1980). Effective porosity is the amount of interconnected pore space that is available for fluid flow. For the relatively large-grained materials likely to be associated with wetlands in central Florida, effective and total porosity are nearly the same.

\begin{tabular}{lc}
\hline \multicolumn{1}{c}{ Material } & $\begin{array}{c}\text { Porosity, } \\
\text { percent by volume }\end{array}$ \\
\hline Fine gravel & 34 \\
Coarse sand & 39 \\
Medium sand & 39 \\
Fine sand & 43 \\
Silt & 46 \\
\hline
\end{tabular}

The following values of maximum and minimum soil moisture content are taken from Nofziger and Hornsby, 1985. They are listed in percent by volume. To convert to fraction of total porosity, divide the values from the table by porosity, in percent.

\begin{tabular}{lcc}
\hline \multirow{1}{*}{ Soil name } & \multicolumn{2}{c}{ Water content } \\
& (in percent by volume) \\
\cline { 2 - 3 } & Maximum & Minimum \\
\hline Sparr Fine Sand & 21.6 & 9.5 \\
Arredondo Fine Sand & 20.4 & 9.1 \\
Gainesville Sand & 14.8 & 5.8 \\
Orangeburg Fine Sandy Loam & 30.3 & 15.8 \\
Chaires Fine Sand & 25.9 & 8.7 \\
Troup Fine Sand & 25.1 & 11.8 \\
Fuquay Fine Sand & 23.5 & 12.9 \\
Myakka Fine Sand & 13.2 & 2.5 \\
Lakeland Fine Sand & 7.7 & 1.5 \\
Blanton Fine Sand & 16.4 & 6.3 \\
Tavares Fine Sand & 8.2 & 0.9 \\
\hline
\end{tabular}

\section{Appendix II - Documentation for tank model}

\section{Description of Files}

Files and formats for data are described in this appendix. Numerical data that do fill the entire specified range of columns should be right-justified, with the decimal included unless the data type is integer. Character data should be left justified.

\section{Rainfall}

A data base of daily rainfall in ASCII data type is required for this model. Although the model reads date and outputs date to screen during processing, it does not keep track of skips in record. Therefore, the records in the data base are assumed to be consecutive days. Each record of the database has the following format:

Columns 5-10 (integer): Date, in YYMMDD format

Columns 11-20 (Real): Daily rainfall, in inches 


\section{Rainfall File}

A file of daily rainfall in ASCII data type is required for this model. Although the model reads the date and outputs date to the screen during processing, it does not keep track of missing record. Therefore, the records in the file are assumed to be consecutive days. Each record in the database has the following format:

Columns 5-10 (integer): Date, in YYMMDD format

Columns 11-20 (Real): Daily rainfall, in inches

\section{Evaporation File}

This file consists of a single record containing the estimated daily potential evapotranspiration (PET) averaged for each month of the year.

Columns 1-5: January PET, in inches per day

6-10: February PET

16-20: April PET

21-25: May PET

26-30: June PET

31-35: July PET

36-40: August PET

41-45: September PET

46-50: October PET

51-55: November PET

56-60: December PET

\section{Control and Unit Tank Description File}

This file contains three different types of information that are specified by the user. First, it contains the user-selected names for the (1) rainfall, (2) PET, and (3) output (containing simulated values) files. Next, the control and unit tank description contains values for the number of iterations selected for each day, output control variable specifying what data are to be written to output files, and the number of unit tanks used in the simulation.

The name of the control and unit tank description file is entered from the keyboard when requested, and is the only direct keyboard input required by the model.

Record 1 (input rainfall file names):

Columns 1-40 (Character): Name of the input rainfall file.

Record 2 (input PET file name)

1-40 (Character): Name of the input PET file. 


\section{Record 3 (output file name):}

Columns 1-40 (Character): Name of the output data file.

\section{Record 4 (iteration control):}

Columns 1-10 (integer): Number of iterations per day.

\section{Record 5 (Tank number for simulated values output):}

Columns 1-10 (integer): Output control: The tank number for which simulated daily values are to be output.

\section{Record 6 (Output-variable identifier):}

Columns 1-10 (integer): Code number of the output variable:

1: Water level 2: Ground-water inflow 3: Surface inflow

4: Rainfall 5: Evapotranspiration 6: Surface Outflow

7: Ground-water outflow 8. Leakage

\section{Record 7 (Output-variable units identifier):}

Columns 1-10 (integer): Code number for selection of daily value output units. Enter 1 for inches, or 2 for cubic ft per sec. Regardless of the units selected here, the water level output, if requested, will be in feet.

\section{Record 8 (Number of tanks):}

Columns 1-10 (integer): The total number of tanks in the simulation.

The following records specify data for the tanks in the simulation. Each record contains data for a single parameter, and the data values for the individual tanks are given in specific columns, in fields of 10 characters. Values for tank 1 are in columns 11-20, values for tank 2 are in 21-30, and so forth. Therefore, there are as many columns of tank data as there are tanks specified in record 8 , and the record length will exceed 80 characters if more than 7 tanks are defined. The first 10 columns of the records are not used by the model and may be used to annotate the record for convenience in editing.

\section{Record 9 (Tank number for each tank):}

Columns 11-20, 21-30, ...(integer): A number used to identify the tanks used in the simulation.

\section{Record 10 (Destination of surface outflow for each tank):}

Columns 11-20, 21-30, ...(integer): The tank number of the tank which receives the surface outflow from this tank. A 0 is used if the outflow is not to be directed to any other tank.

\section{Record 11 (Destination of ground-water outflow for each tank):}

Columns 11-20, 21-30, ...(integer): The tank number of the tank which receives the ground-water outflow from this tank. A 0 is used if the outflow is not to be directed to any other tank.

\section{Record 12 (The initial water level in each tank):}

Columns 11-20, 21-30, ...(real): The beginning water level, in feet.

\section{Record 13 (Downward leakage rate):}

Columns 11-20, 21-30, ...(real): The downward leakage rate, from the surficial aquifer system to the Upper Floridan aquifer, in $\mathrm{ft} / \mathrm{day}$. 
Record 14 (Soil porosity):

Columns 11-20, 21-30, ...(real): The porosity of the soil (ratio of void volume to total soil volume).

\section{Record 15 (Maximum moisture content):}

Columns 11-20, 21-30, ...(real): The field capacity, or maximum moisture content the soil can contain before downward seepage occurs, in fraction of porosity.

\section{Record 16 (Minimum moisture content):}

Columns 11-20, 21-30, ...(real): The wilt potential, or minimum moisture content, in fraction of porosity.

\section{Record 17 (Land-surface elevation):}

Columns 11-20, 21-30, ...(real): The land-surface elevation, in $\mathrm{ft}$.

Record 18 (Extinction depth):

Columns 11-20, 21-30, ...(real): The extinction depth, in $\mathrm{ft}$.

\section{Record 19 (Drainage area):}

Columns 11-20, 21-30, ...(real): The tank's drainage area, in either relative units or square miles, according to the type of units selected for output in record 4 . If output units are in., then relative tank sizes should be specified, with the downstream tank having a size of 1 . If output units are in $\mathrm{ft}^{3} / \mathrm{s}$, then the tank sizes should be in $\mathrm{mi}^{2}$.

\section{Record 20 (Surface runoff rate):}

Columns 11-20, 21-30, ...(real): Surface-runoff rate coefficient, in 1/day.

Record 21 (Ground-water runoff rate):

Columns 11-20, 21-30, ...(real): Ground-water runoff rate coefficient, in 1/day.

An example of a control file defining a 3-tank simulation is given on next page. Descriptive information is shown in parenthesis but is not part of the model input. 


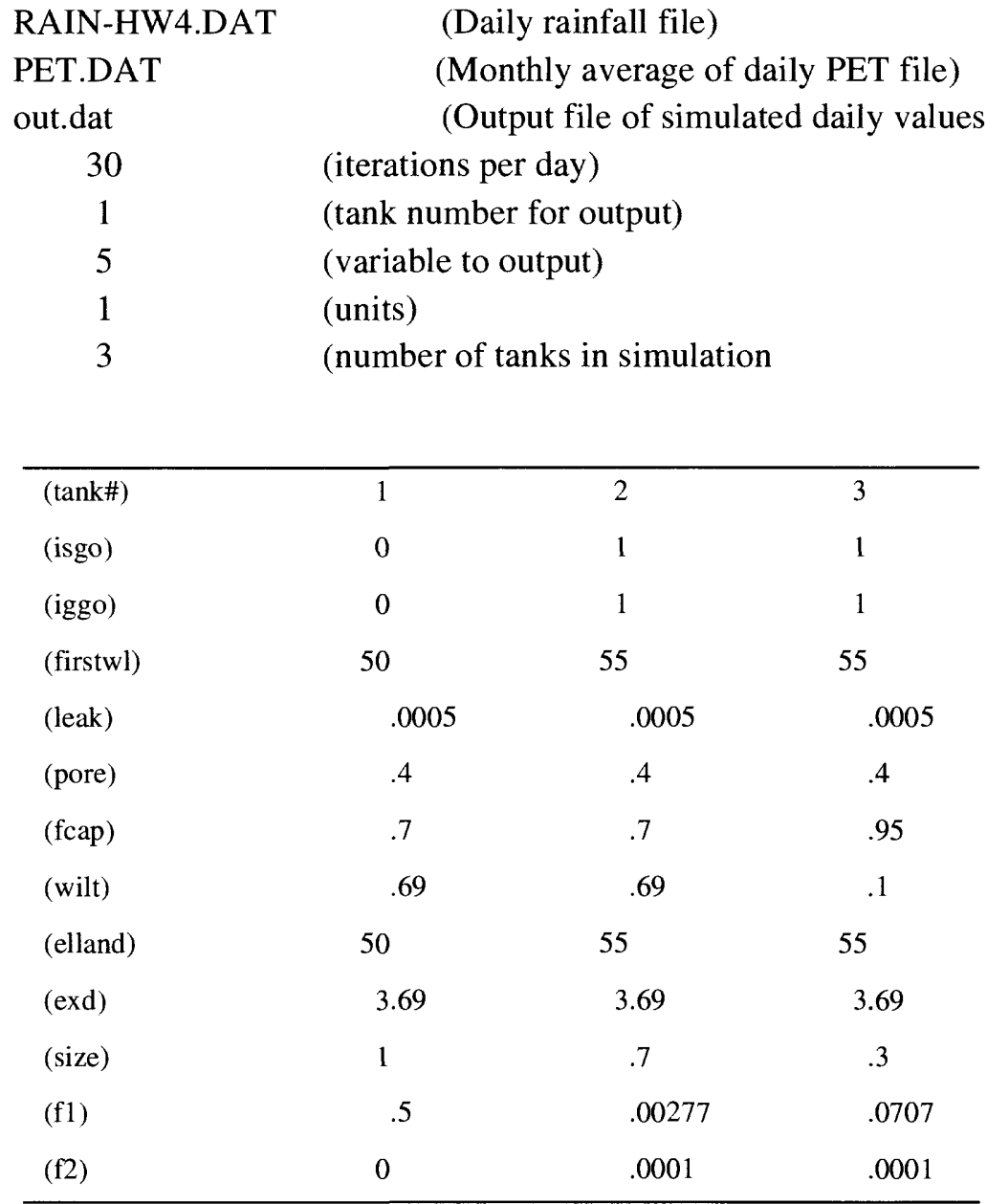

\section{Description of Output}

Two types of output are generated by this model. One type is an ASCII file that contains records of the date and the daily values requested in record 4 of the control and tank description file. Each record (day) has the following format: Columns 1-8, date, in YY-MM-DD notation; columns 9-18, daily value of the selected variable. Water levels are in feet, evapotranspiration and rainfall are in inches, and the other variables that may be selected for output are in either inches $\mathrm{ft}^{3} / \mathrm{s}$, as selected.

The other type of output is to the computer screen. This output summarizes the model run in terms of total quantities of water for the period of simulation, and error in the water balance. Water quantities are all in inches, regardless of the units selected for file output. A sample output for a three-tank model follows:

Number of days: 741

Number of iterations per day: 30

The daily output is in out.dat

The output variable is water_level for tank 1

Daily output units are feet 


\begin{tabular}{ccccccc}
\multicolumn{6}{c}{ tank } & \multicolumn{6}{c}{ ingw } & insw & rain & delstore & delsoil \\
1 & 3.7636 & 4.1906 & 90.0500 & -5.1725 & 3.6187 \\
2 & 0.0000 & 0.0000 & 90.0500 & -6.5725 & 4.5983 \\
3 & 0.0000 & 0.0000 & 90.0500 & -75.7538 & 60.0472 \\
& & & & & \\
tank & et & outgw & outsw & leak & \\
1 & 77.1736 & 0.0000 & 17.6378 & 4.4460 & \\
2 & 79.9818 & 4.6314 & 2.8631 & 4.4460 & \\
3 & 91.9864 & 1.7392 & 7.2880 & 4.4460 &
\end{tabular}

----TOTAL INFLOWS AND OUTFLOWS, IN INCHES, AND HYDROPERIOD-.

\begin{tabular}{crcccc} 
& & & & \multicolumn{2}{c}{ hydroperiod } \\
tank & total in & total out & \% error & days & percent \\
1 & 99.5580 & 99.2574 & 0.3019 & 86 & 12 \\
2 & 92.0242 & 91.9223 & 0.1107 & 289 & 39 \\
3 & 105.7566 & 105.4597 & 0.2808 & 133 & 18
\end{tabular}

The number of days, number of iterations per day, and identification of the output simulated data is listed first, followed by the water-balance summary for each tank. Ingw is the ground-water discharge into the tank, insw is the surface inflow, rain is the rainfall, et is the total amount of ET removed from the water table and the soil, delstore is the change in storage of water in the tank from start to end of the run, delsoil is the change in moisture storage in the soil, outgw is the discharge of ground water from the tank (not including the downward leakage), outsw is the surface outflow from the tank, and leak is the downward leakage from the tank.

In this sample output, the ground and surface outflows of tanks 2 and 3 were directed into tank 1 . Therefore, the inflows to tank 1 are the size-weighted sums of the outputs from tanks 2 and 3 . Sizes in this example were set at 1.0 for tank $1,0.7$ for tank 2 , and 0.3 for tank 3 .

Following the water-budget summary is the summary of total inflow (total in), outflow (total out), percent difference between inflow and outflow (\% error), and hydroperiod length. The hydroperiod length is the total number of days of the simulation that the simulated water level was at or above land surface, and is given in days (days) and percent of the total number or days of simulation (percent). Total inflow is ingw + insw + rain $=$ delstore $=$ delsoil. Total outflow is et + outgw + outsw + leak. All flow quantities are given in inches, regardless of the units selected for output of the daily values.

\section{Appendix III - Contents of disk}

The floppy disk included with this report contains the following files:

PET.DAT: a file of monthly potential evapotranspiration, estimated from pan evaporation data for Lisbon and Gainesville using monthly pan coefficients (Kohler, 1954).

RAIN-44.DAT: a file of daily rainfall at the HW44 well field for June 20, 1992 through June 30, 1994.

RAIN-LT.DAT: a file of daily rainfall for Deland, January 1, 1931 through December 31, 1989.

TANK.F: The FORTRAN source listing of the water-budget model.

TANK.DAT: A sample of the data file required for running the model. 


\section{Appendix IV - Source listing of the model, in FORTRAN}

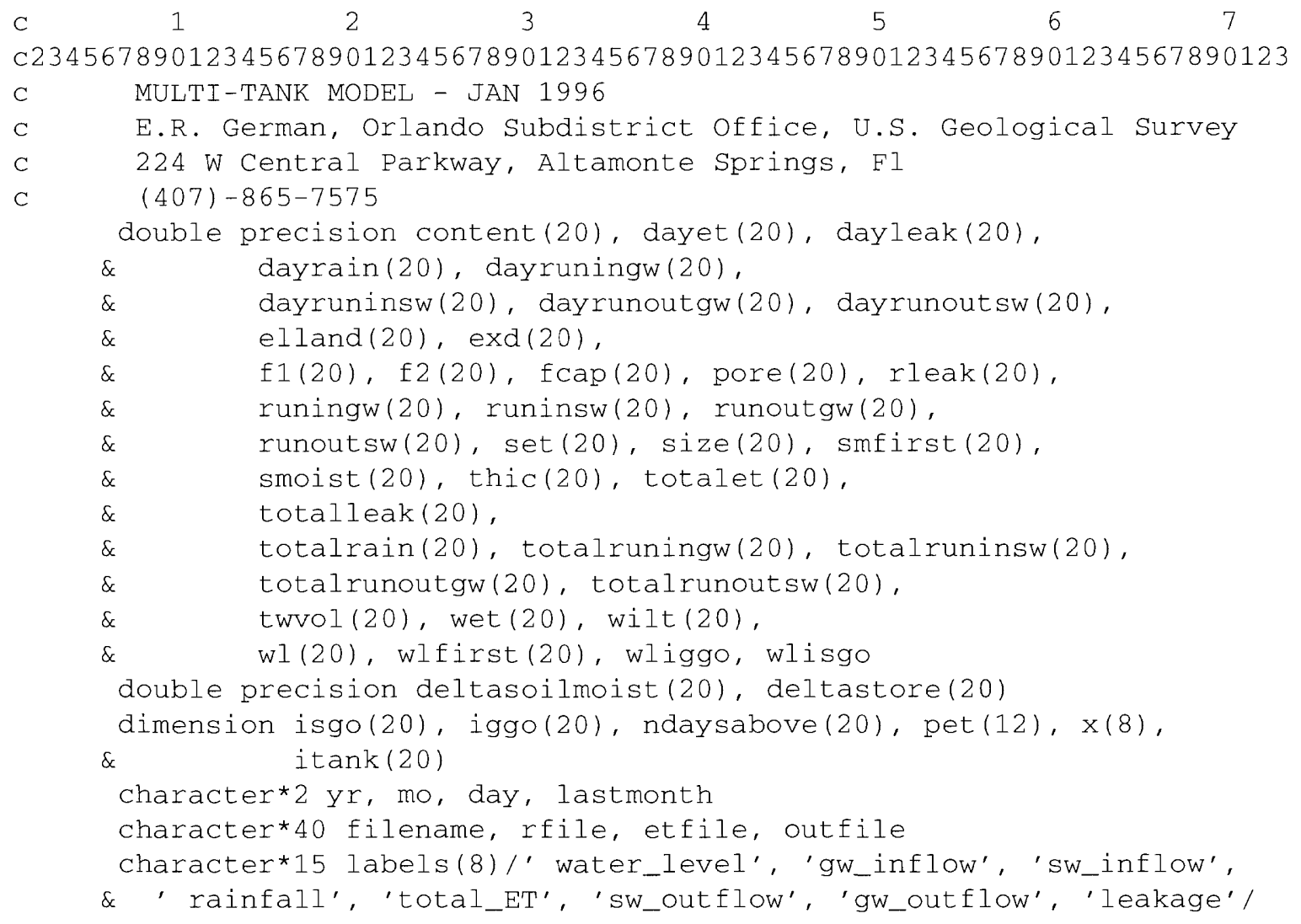

READ IN THE PET DATA 


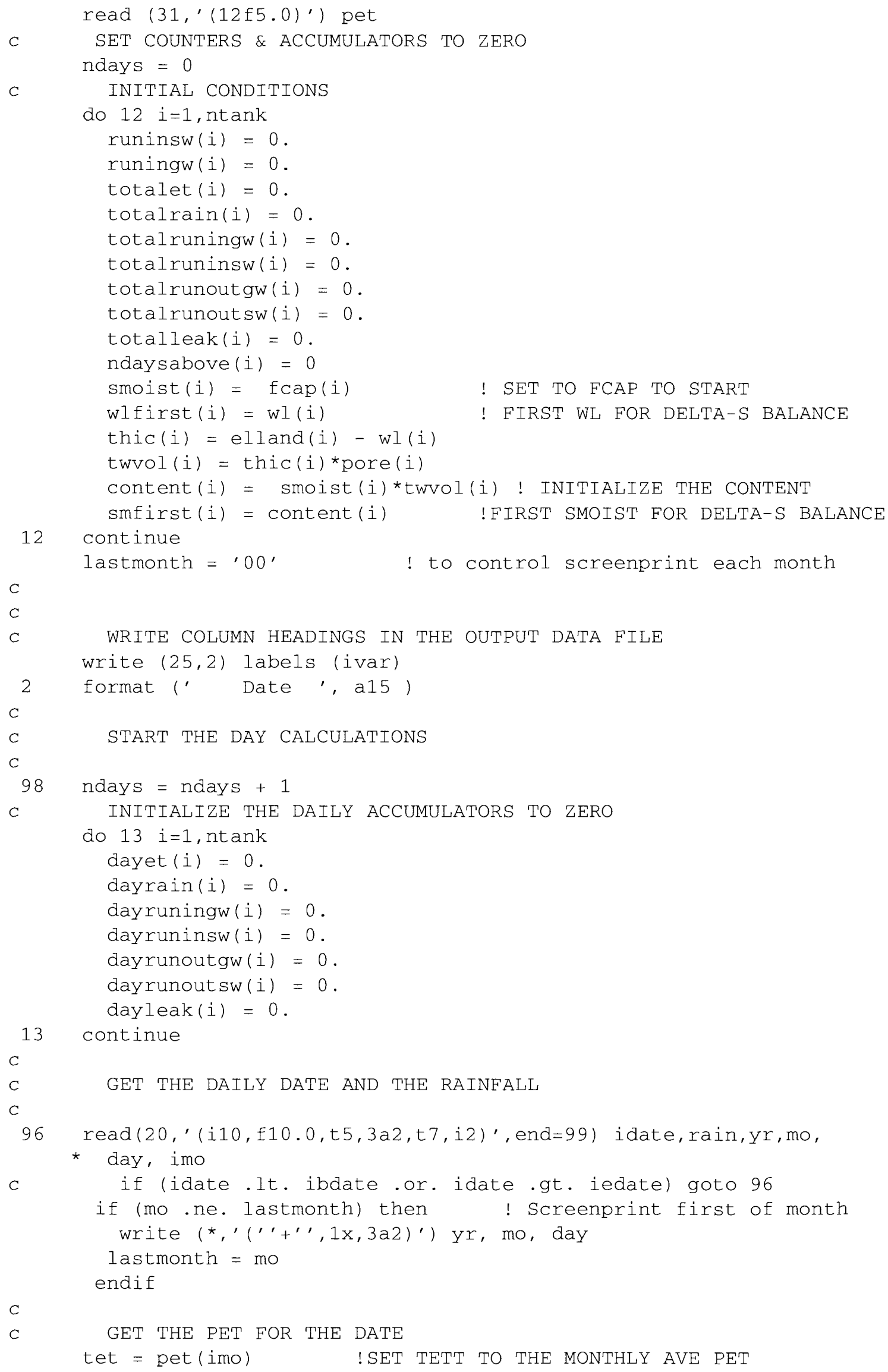




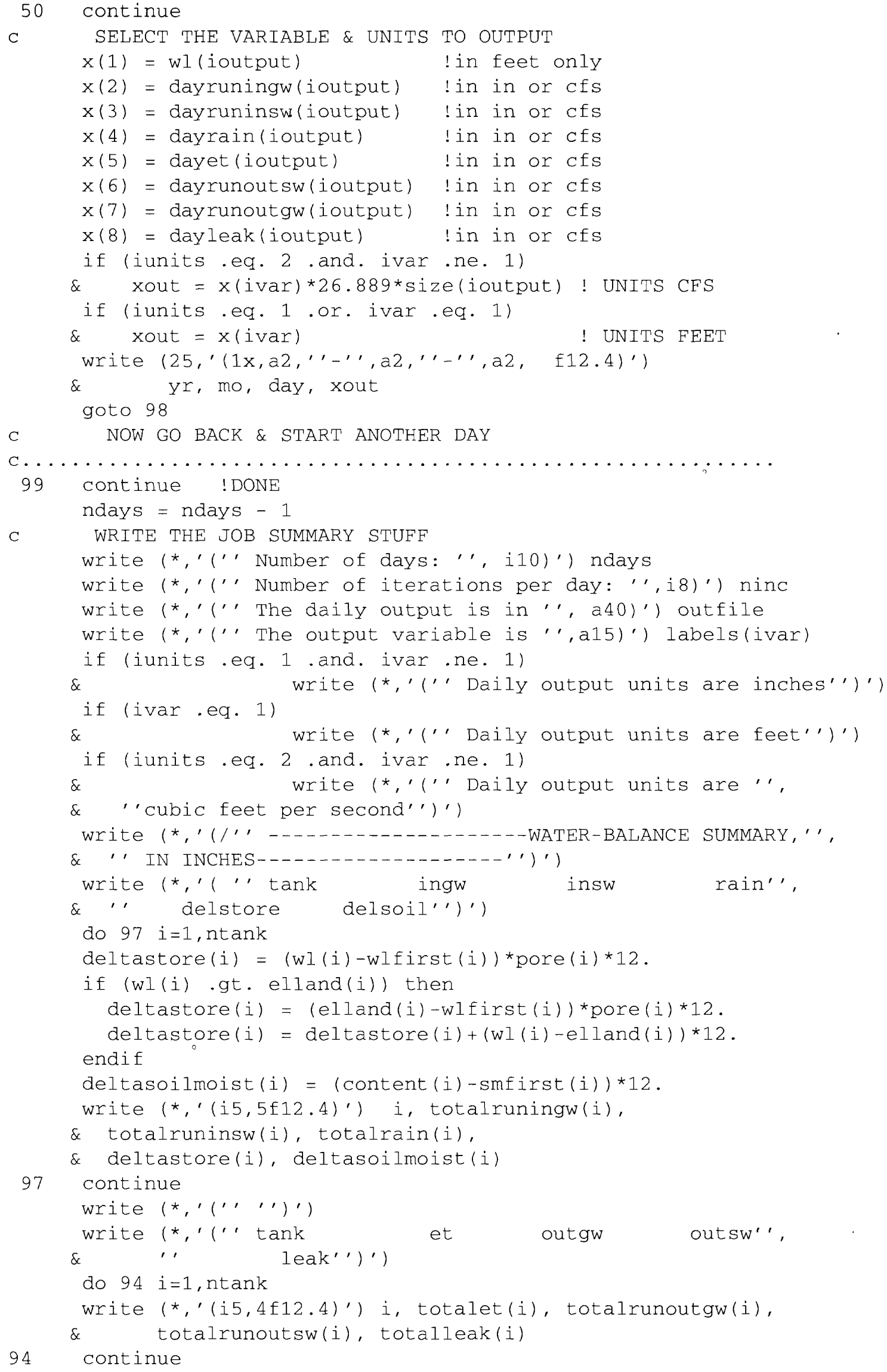




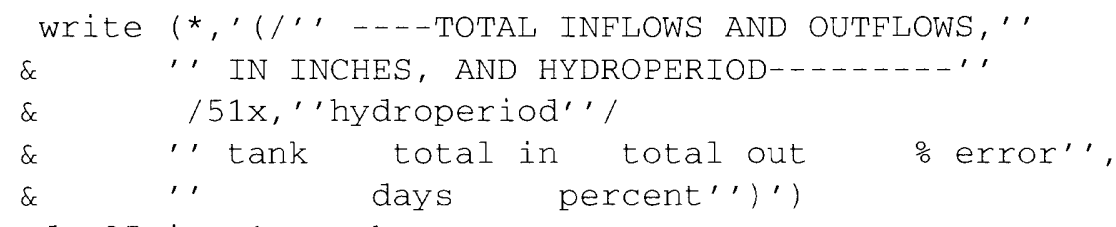

do $95 i=1$, ntank

qinn = totalrain $(i)-\operatorname{deltastore}(i)-\operatorname{deltasoilmoist}(i)$

$\& \quad+$ totalruningw $(i)+$ totalruninsw $(i)$

qout $=$ totalet $(i)+\operatorname{totalleak}(i)+\operatorname{totalrunoutsw}(i)$

$\& \quad+$ totalrunoutgw $(i)$

percent $=100.0 *($ qinn-qout $) /$ qinn

$\mathrm{ip}=0.5+(100 * \mathrm{float}$ (ndaysabove $(i)) /$ ndays $)$

write (*,' (i5,3f12.4,2i12)')

\& $\quad i$, qinn, qout, percent, ndaysabove(i), ip

continue

write $(*, *)$ 'I am now done'

stop

end

subroutine tanku (j, content, dayet, dayleak, dayrain,

\& dayruningw, dayruninsw, dayrunoutgw, dayrunoutsw,

$\&$ elland,

\& f1, f2, fcap, ninc, pore,

\& rain, rleak, runingw, runinsw,

\& runoutgw, runoutsw, set, size,

$\&$ smoist, thic, totalet, totalleak, totalrain,

$\&$ totalruningw, totalruninsw, totalrunoutgw,

\& totalrunoutsw, twvol,

\& wet, wilt, wl, wliggo, wlisgo)

double precision content, dayet, dayleak,

$\begin{array}{ll}\& & \text { dayrain, dayruningw, dayruninsw, dayrunoutgw, } \\ \& & \text { dayrunoutsw, elland, exd, } \\ \& & \text { f1, f2, fcap, pore, rleak, } \\ \& & \text { runingw, runinsw, runoutgw, } \\ \& & \text { runoutsw, set, size, } \\ \& & \text { smoist, thic, totalet, totalleak, } \\ \& & \text { totalrain, totalruningw, totalruninsw, } \\ \& & \text { totalrunoutgw, totalrunoutsw, } \\ \& & \text { twvol, wet, wilt, } \\ \& & \text { wl, wliggo, wlisgo }\end{array}$

double precision a

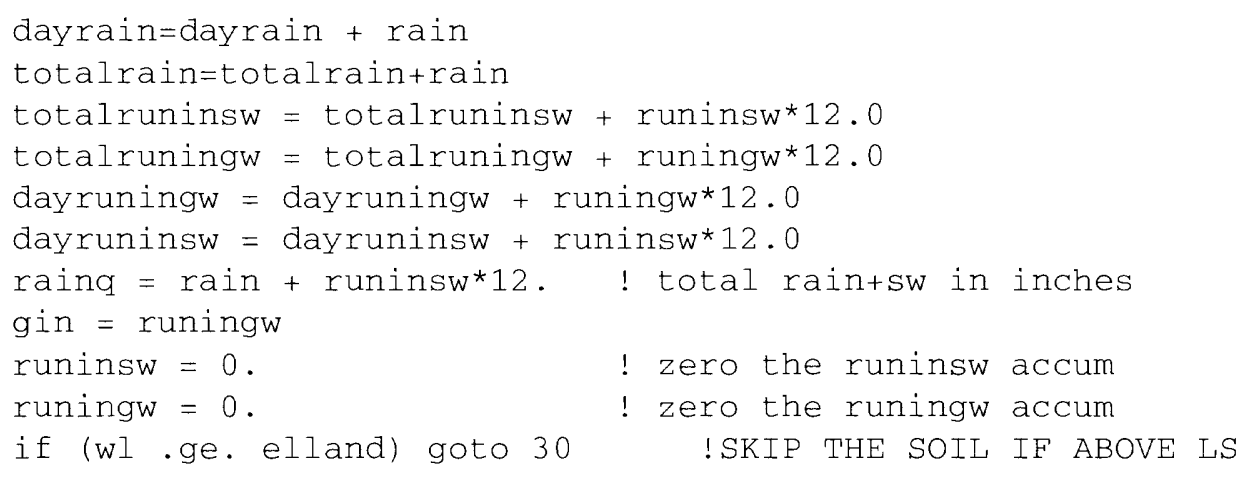


C

C

C

19 continue

call zero (cap)

call zero (contest)

C

Put in the rain

smoist $=\mathrm{fcap}$

else

raing $=0$.

endif

call zero (rainq)

continue

else

endif

continue if (rainq.1t. 1e-20) goto 15 ! SKIP THE RAIN, GOTO THE EVAP

if ( cap . . It. 1e-20) goto 15

if (rainq/12. gt. cap) then ! SOIL WET, SOME RAIN TO WTABLE

rainq $=$ rainq $-\operatorname{cap} * 12$.

content $=$ twvol* $\mathrm{fcap}$

! SOIL CAN HOLD ALL RAIN

content $=$ content + rainq/12.

smoist $=$ content / twvol

Take out the et

if (set.1t. 1e-20) goto 19

if (twrol.1t. 1e-20) goto 19

if (wl.gt. elland) goto 30

contmin = wilt*twvol

if (content.le. contmin) goto 19

if (set/12. .gt. content-contmin) then !SOIL DRYS TO WILT

totalet $=$ totalet $+12 *($ content-contmin $)$

dayet $=$ dayet $+12 *($ content - contmin $)$

content $=$ contmin

smoist $=$ content $/$ twvol

!SOIL DOSN'T GO DRY

content $=$ content - set/12.

smoist $=$ content $/$ twvol

totalet $=$ totalet + set

dayet $=$ dayet + set

SKIP TO HERE FROM et IF WL > ELLAND

totalet $=$ totalet + wet

dayet $=$ dayet + wet

DOWNWARD LEAKAGE FROM SURFICIAL TO FLORIDAN

wleak = rleak/float $($ ninc)

totalleak $=$ totalleak + wleak $* 12$.

dayleak = dayleak + wleak*12.

CALCULATE THE RUNOUTSW FROM THE WETLANDS

if (wl .gt. elland and. wl . gt. wlisgo) then

runoutsw $=(\mathrm{wl}-\mathrm{elland}) * \mathrm{fl} / \mathrm{float}$ (ninc) ! IN FEET

totalrunoutsw $=$ totalrunoutsw + runoutsw*12. ! IN INCHES

dayrunoutsw $=$ dayrunoutsw + runoutsw ${ }^{\star} 12.0$

else

runoutsw $=0$. 
endif

C CALCULATE THE GW RUNOUT

grad $=w l-w l i g g o$

if (grad.gt. 0) then

runoutgw $=\mathrm{f} 2{ }^{*} \mathrm{grad} / \mathrm{float}(\mathrm{ninc})$

dayrunoutgw $=$ dayrunoutgw + runoutgw $w^{\star} 12 . \quad$ ! IN INCHES

totalrunoutgw $=$ totalrunoutgw + runoutgw ${ }^{\star} 12$. ! IN INCHES

else

runoutgw $=0$.

endif

C CALCULATE THE CHANGE IN WL

up $=$ rainq/12. + gin

down $=$ wet $/ 12 .+$ wleak + runoutsw + runoutgw

delta $=$ up - down

if (delta.ge. 0. .and. wl .1t. elland) then

C

ACCOUNT FOR THE SOIL MOISTURE SWALLOWED BY THE WL RISE

$\mathrm{d}=\mathrm{delta} /($ pore* $(1 . \mathrm{d} 0$ - smoist))

if ( $d$.gt. (elland-wl) ) $d=e l l a n d-w l$ ! DON'T LET IT RISE ABOVE LS

$\mathrm{wl}=\mathrm{wl}+\mathrm{d}$

!SMOIST $\%$ DOES NOT CHANGE

thic $=$ elland-wl

twrol $=$ thic $^{\star}$ pore

content $=$ smoist $*$ twvol

return

endif

C KEEP THE FIELD CAPACITY MOISTURE IN THE SOIL IF WL DECLINES

if (delta.lt. 0. and. wl .lt. elland) then

$\mathrm{d}=$ delta/(pore*(1.0d0-fcap)) ! THE DECLINE IN WATER LEVEL

$\mathrm{wl}=\mathrm{wl}+\mathrm{d}$

thic $=$ elland-wl

twvol $=$ thic $^{*}$ pore

content $=$ content $-d^{\star}$ pore ${ }^{\star}$ fcap !SUBTRACT 'CAUSE DELTA IS NEG.

smoist $=$ content $/$ twvol

return

endif

C WHEN THE WATER LEVEL IS ABOVE LAND SURFACE

if (wl ge. elland) then

if (delta.lt. 0. .and. delta.lt. elland-wl)

$\&$

delta $=$ elland $-\mathrm{wl}$

$\mathrm{w} l=\mathrm{wl}+$ delta

if (wl .1t. elland) then

smoist $=$ fcap

thic $=$ elland-wl

twvol $=$ thic*pore

content $=$ twvol*fcap

endif

return

endif

end

subroutine zero (x)

if $(x \cdot 1 t \cdot 1 \cdot e-20$. and $x \cdot g t \cdot-1 \cdot e-20) x=0$.

return

end 